Research review paper

\title{
Metabolic engineering of Saccharomyces cerevisiae for the production of top value chemicals from biorefinery carbohydrates
}

\author{
Sara L. Baptista ${ }^{1}$, Carlos E. Costa ${ }^{1}$, Joana T. Cunha, Pedro O. Soares, Lucília Domingues \\ CEB - Centre of Biological Engineering, University of Minho, Campus Gualtar, Braga, Portugal
}

\section{A R T I C L E I N F O}

\section{Keywords:}

Saccharomyces cerevisiae

Metabolic engineering

High-value biobased products

Biorefineries

Renewable carbon sources

\begin{abstract}
A B S T R A C T
The implementation of biorefineries for a cost-effective and sustainable production of energy and chemicals from renewable carbon sources plays a fundamental role in the transition to a circular economy. The US Department of Energy identified a group of key target compounds that can be produced from biorefinery carbohydrates. In 2010, this list was revised and included organic acids (lactic, succinic, levulinic and 3-hydroxypropionic acids), sugar alcohols (xylitol and sorbitol), furans and derivatives (hydroxymethylfurfural, furfural and furandicarboxylic acid), biohydrocarbons (isoprene), and glycerol and its derivatives. The use of substrates like lignocellulosic biomass that impose harsh culture conditions drives the quest for the selection of suitable robust microorganisms. The yeast Saccharomyces cerevisiae, widely utilized in industrial processes, has been extensively engineered to produce high-value chemicals. For its robustness, ease of handling, genetic toolbox and fitness in an industrial context, $S$. cerevisiae is an ideal platform for the founding of sustainable bioprocesses. Taking these into account, this review focuses on metabolic engineering strategies that have been applied to $S$. cerevisiae for converting renewable resources into the previously identified chemical targets. The heterogeneity of each chemical and its manufacturing process leads to inevitable differences between the development stages of each process. Currently, 8 of 11 of these top value chemicals have been already reported to be produced by recombinant $S$. cerevisiae. While some of them are still in an early proof-of-concept stage, others, like xylitol or lactic acid, are already being produced from lignocellulosic biomass. Furthermore, the constant advances in genomeediting tools, e.g. CRISPR/Cas9, coupled with the application of innovative process concepts such as consolidated bioprocessing, will contribute for the establishment of $S$. cerevisiae-based biorefineries.
\end{abstract}

\section{Introduction}

In a broad sense, biorefining is described as the sustainable processing of biomass into a range of marketable biobased products and bioenergy (IEA Bioenergy, 2008). The biorefinery concept comprehends the use of a spectrum of technologies to convert renewable resources, such as lignocellulosic biomass, crude glycerol or cheese whey, into the respective building blocks that can be used for the production of biofuels, chemicals or other value-added compounds (Cherubini, 2010). Contrary to the petroleum-based refinery, where natural resources are largely exploited with tremendous waste production, biorefinery embodies a major shift by integrating systems that enable full resource usage (Cherubini, 2010). The establishment of a biorefinery fulfils two main purposes: an energy goal, which is driven by the need of renewable energy sources; and an economic goal, focusing on the development of a biobased industry capable of generating profit (Bozell and Petersen, 2010). Considering this, Bozell and Petersen (2010) presented a revised list of biobased product opportunities from renewable carbohydrates, based on the one published in 2004 by the US Department of Energy (Werpy and Petersen, 2004). Based on technological advances, the new top chemical opportunities comprise ethanol, organic acids (lactic, succinic, levulinic and 3-hydroxypropionic acids), sugar alcohols (xylitol and sorbitol), furans (hydroxymethylfurfural, furfural and furandicarboxylic acid), biohydrocarbons (isoprene), glycerol and its derivatives (Bozell and Petersen, 2010). These top value biobased chemicals were selected following specific criteria such as knowledge on conversion technology, economic value, industrial viability, size of markets and the ability of a compound to serve as a platform for the production of derivatives. These compounds have been recently the focus of a review that highlighted the recent techniques developed for

\footnotetext{
* Corresponding author.

E-mail address: luciliad@deb.uminho.pt (L. Domingues).

$1+$ These authors contributed equally to this work.
} 
their production (mainly chemical) within a biorefinery and the status for its commercialization (Takkellapati et al., 2018). Although the energy goal is addressed by the efforts made in the biofuel industry, fuel is considered a low value product. Despite its high volume production, it has limited returns on the funding needed to establish a biorefinery, becoming a barrier to achieve the economic goal (Bender et al., 2018). Therefore, a biorefinery able to complement biofuel production with high-value biobased products can effectively aid in the reduction of nonrenewable fuel consumption and simultaneously deliver the economic incentive to expand the biorefining industry (Wu et al., 2016).

Lasure and Zhang (2003) proposed that the biorefinery future would be based on the conversion of lignocellulosic biomass into an array of useful products, where raw materials are separated into different components that can be converted into a target compound. Lignocellulosic biomass is the most available renewable resource on the planet, and it is considered an alternative to fossil carbon sources. Lignocellulosic biomass pretreatment is an essential step to break down its recalcitrant structure into cellulose, hemicellulose and lignin, enhancing the enzymatic access to cellulose and solubilization of hemicellulose into oligosaccharides and monosaccharides (Mes-Hartree et al., 1988; Romaní et al., 2014). However, this leads to the formation of inhibitory compounds like weak acids, furans and phenolic compounds (Palmqvist and Hahn-Hagerdal, 2000; Cunha et al., 2019a). In this sense, some requirements are mandatory for an integrated sustainable process: (1) identification of tolerance determinants (Gorsich et al., 2006; Mira et al., 2010; Pereira et al., 2011); (2) (over)expression of genes involved in tolerance response (Larsson et al., 2001; Cunha et al., 2015; Cunha et al., 2018a); (3) utilization of a robust microorganism able to cope with these stress factors (Tomás-Pejó et al., 2008; Pereira et al., 2014; Costa et al., 2017). Different biorefinery concepts comprising bioethanol production have been proposed (Romaní et al., 2016a, 2016b; Domínguez et al., 2017; Jesus et al., 2017; del Río et al., 2019) and significant advances have been made for the overall valorisation of lignocellulosic biomass.

In an industrial perspective, microbial production of biofuels and chemicals has been receiving increased interest, as it allows the use of renewable feedstocks and a subsequent production of building blocks at a lower cost than by traditional routes (Borodina and Nielsen, 2014). Among the compounds targeted by the chemical industry, some are not naturally produced by microorganisms or are produced with low yields and titres, with accumulation of by-products throughout the process. Advances in biotechnological production of chemicals and biofuels are motivated by innovative strategies of genetic engineering, encompassing DNA technology breakthroughs, which enable the creation of superior cell factories (Becker et al., 2015). An industrial cell factory must comprise commercial requirements for yield, productivity and titre (Hong and Nielsen, 2012). A cell factory can either be used for de novo synthesis, involving complex metabolic pathways to produce a compound from a simple molecule (e.g. glucose), or for biotransformation, in which a specific reaction produces a compound structurally similar to the substrate molecule. Several microorganisms including Escherichia coli, Bacillus subtilis, Saccharomyces cerevisiae, Aspergillus niger, among others, have been improved for commercial application (Hong and Nielsen, 2012). The yeast $S$. cerevisiae stands out as an attractive cell factory, since it is commonly used in several microbiological industrial processes, such as the production of beer, bread, wine, bioethanol, nutraceuticals, chemicals, and pharmaceuticals (Nielsen and Jewett, 2008). In addition, this yeast is generally regarded as safe (GRAS status) and has been engineered with a variety of genetic tools to be able to efficiently cope with several harsh fermentation conditions like high temperature, low $\mathrm{pH}$ and the presence of inhibitory compounds (Hong and Nielsen, 2012; Borodina and Nielsen, 2014). Furthermore, industrial $S$. cerevisiae isolates have received special attention due to their higher robustness, fermentation capacity and resistance to stress factors when compared with laboratory strains (Pereira et al., 2010). Particularly over the past decade, there have been joint efforts between academia and industry to develop processes for fermentation of lignocellulosic hydrolysates with engineered S. cerevisiae strains (Cunha et al., 2020), leading to the advent of second-generation ethanol plants, either at a demonstration or full commercial scale (Jansen et al., 2017).

Considering that ethanol has been the focus of several studies describing genetic engineering of $S$. cerevisiae to improve its production (recently and extensively reviewed by Görgens et al., 2015; Ko and Lee, 2018; Nijland and Driessen, 2020; Cunha et al., 2020), in this review we address the economic goal of the biorefinery concept, focusing on the high-value low-volume compounds previously identified by Bozell and Petersen (2010). Considering that the conversion of renewable carbon into chemicals is the most challenging and least developed step of all biorefinery operations, this review aims to enlighten the putative role of $S$. cerevisiae as a microbial cell factory for integrated biorefineries. Therefore, and bearing in mind that a decade has passed since the update of the list of top chemical opportunities from biorefinery carbohydrates, we provide an overview of the genetic engineering strategies previously applied in $S$. cerevisiae to improve the feasibility of a biorefinery implementation through the production of the identified top value compounds.

\section{Top value biobased chemicals production}

\subsection{Organic acids: lactic, succinic, levulinic and 3-hydroxypropionic} acids

Organic acids are important building block chemicals with massive market potential. They present low molecular weight, one or more acidic groups (such as carboxyl, sulfonic, alcohol, phenol, among others) and its production is mainly petroleum-based (Yin et al., 2015). Successful case studies of the different organic acids produced by engineered $S$. cerevisiae are listed in Table 1.

\subsubsection{Lactic acid}

Lactic acid (LA) is the most widespread hydroxycarboxylic acid in nature, being produced by many organisms by fermentation of glucose and other feedstocks (Borodina and Nielsen, 2014). LA is a valuable chemical with several applications in food, cosmetic, textile and other industries, and it is a direct product of lactate dehydrogenase (LDH), which converts pyruvate into LA (Sauer et al., 2008). LA market is evaluated in $\$ 1.25$ thousand million as of 2019 , with an estimated compound annual growth rate (CAGR) of $11.5 \%$ between 2020 and 2026 (Global Market Insights, 2020). Industrial-scale production of LA has been in place for a long time, starting in the late $19^{\text {th }}$ century, and even though the chemical production of LA was well-established since the early 1960s (Benninga, 1990), industrial production of LA nowadays is almost entirely biotechnological (Groot et al., 2010). Several companies such as NatureWorks, Purac, Galactic, among others, produce roughly 400 thousand tonnes of LA per year (Becker et al., 2015), mostly using optimized lactobacilli and engineered yeast strains.

Generally, reported studies in LA production follow two main strategies: the expression of heterologous LDH that enables the transformation of pyruvate into LA (Yamada et al., 2017); and the attenuation or deletion of pyruvate decarboxylase (PDC) activity (Novy et al., 2017) to reduce carbon flux to ethanol (Fig. 1). Several studies combine these two strategies for superior LA production. Baek et al. (2016) reported a titre of $48.9 \mathrm{~g} / \mathrm{L}$ of LA without neutralization and $112 \mathrm{~g} / \mathrm{L}$ of LA in fedbatch under neutralizing conditions, using glucose as substrate. This was achieved by expressing the $I d h A$ gene from Leuconostoc mesenteroides allied to the deletion of $P D C 1$ and $A D H 1$ genes to reduce ethanol production. Additional modifications were made to eliminate glycerol production (deletion of GPD1 and GPD2 genes), avoid glucose depletion (knockout of DPD1 and JEN1) and increase LA tolerance by adaptive evolution and HAA1 overexpression (strain JHY5320). Another strategy focused on the deletion of several alcohol dehydrogenase (ADH) genes combined with the expression of ldhA and the knockout of PDC1, GPD1, GPD2 and DPD1 genes. Adaptive laboratory evolution of the engineered 
Table 1

S. cerevisiae metabolic engineering strategies for the production of organic acids (lactic, succinic and 3-hydroxypropionic)

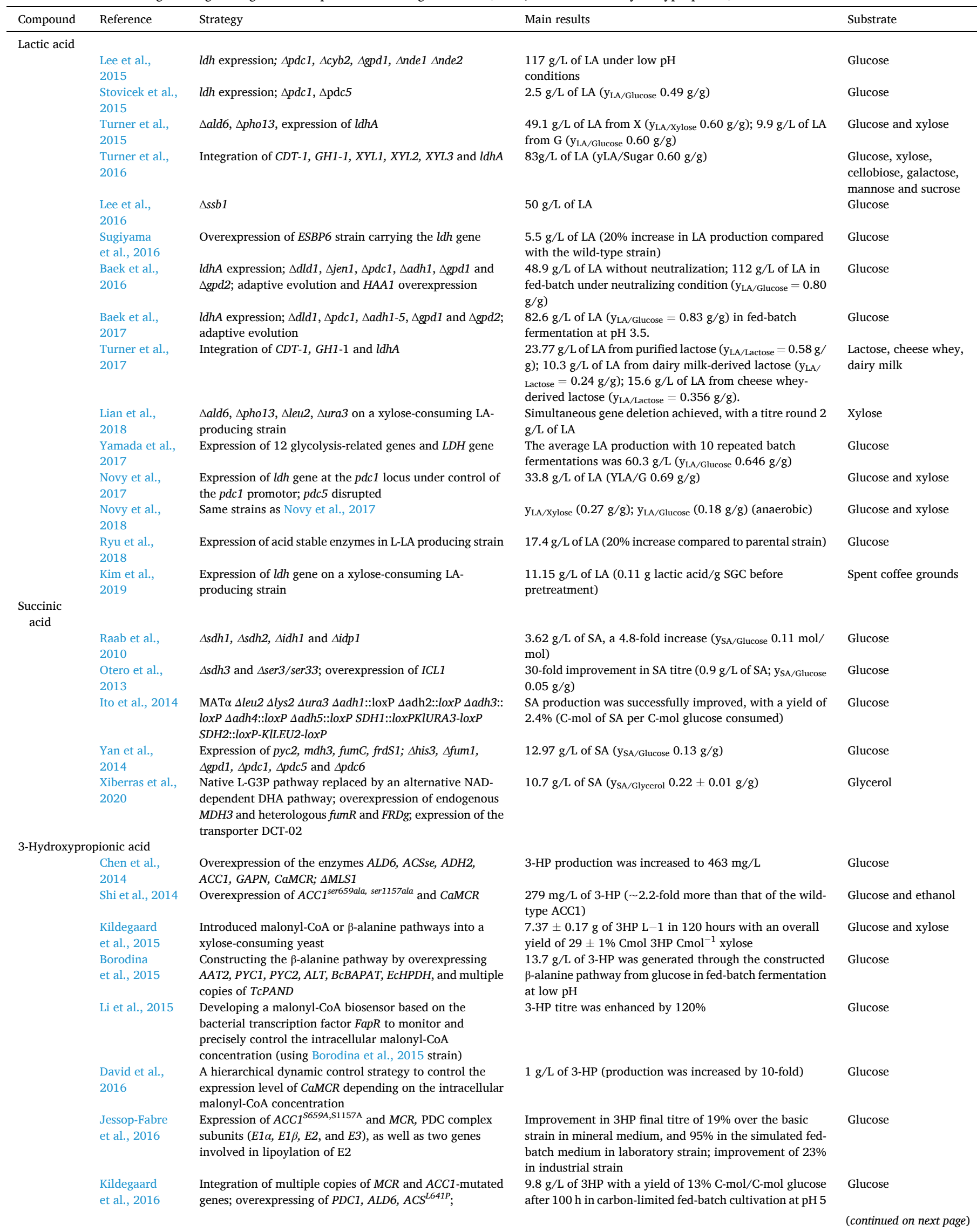


Table 1 (continued)

\begin{tabular}{|c|c|c|c|c|}
\hline Compound & Reference & Strategy & Main results & Substrate \\
\hline & & $\begin{array}{l}\text { engineering of the cofactor specificity of the } \\
\text { glyceraldehyde-3-phosphate dehydrogenase }\end{array}$ & & \\
\hline & $\begin{array}{l}\text { Chen et al., } \\
2017 \text { a }\end{array}$ & $\begin{array}{l}\text { Manipulation the phospholipid synthesis transcriptional } \\
\text { regulators including Ino2p, Ino } 4 \text {, Opi1p, and a series of } \\
\text { synthetic Ino2p variants }\end{array}$ & $477 \mathrm{mg} / \mathrm{L}$ of 3-HP (production was increased by 9 -fold) & Glucose \\
\hline & $\begin{array}{l}\text { Maury et al., } \\
2018\end{array}$ & $\begin{array}{l}\text { A subset of glucose-dependent promoters, } p A D H 2, p I C L 1 \text {, } \\
\text { and } p H X T 7 \text {, were studies for dynamic control of } 3-\mathrm{HP} \\
\text { production }\end{array}$ & $\begin{array}{l}\text { Less than } 0.6 \mathrm{~g} / \mathrm{L} \text { of } 3 \text {-HP. Regulating the } 3 \text {-HP pathway } \\
\text { by the ICL1 promoter resulted in } 70 \% \text { improvement of } 3 \text { - } \\
\text { HP titre in comparison to PGK1 promoter }\end{array}$ & Glucose \\
\hline & Lis et al., 2019 & $\begin{array}{l}\text { Process optimization (advances in small-scale chemostat } \\
\text { cultivation system) using Borodina et al., } 2015 \text { strain }\end{array}$ & $\begin{array}{l}\text { 3-HP yields of } 15.9 \% \mathrm{C} \text {-mol and } 0.45 \mathrm{~g} \mathrm{gCDW}^{-1} \text { under C- } \\
\text { limiting, as well as } 25.6 \% \mathrm{C} \text {-mol and } 0.50 \mathrm{~g} \mathrm{gCDW}^{-1} \text { under } \\
\text { phosphate-limiting conditions }\end{array}$ & Glucose \\
\hline & $\begin{array}{l}\text { Ferreira et al., } \\
2019\end{array}$ & $\begin{array}{l}\text { Fine-tuning of gene expression to enhance endogenous } \\
\text { metabolic fluxes toward increasing levels of acetyl-CoA } \\
\text { and malonyl-CoA }\end{array}$ & Up to $27 \%$ increase in 3 -HP production & Glucose \\
\hline
\end{tabular}

strain led to mutations in the SUR1 and ERF2 genes, resulting in improved LA tolerance and production. When compared to the previous JHY5320 strain, the evolved JHY5730 strain showed an improvement of 1.7-fold in glucose consumption and 1.5-fold in LA production from 100 $\mathrm{g} / \mathrm{L}$ of glucose in shake flask fermentation. Ultimately, the evolved JHY5730 strain produced $82.6 \mathrm{~g} / \mathrm{L}$ of LA, with a yield of $0.83 \mathrm{~g} / \mathrm{g}$ of glucose in a fed-batch strategy under acidic conditions (Baek et al., 2017). Another study highlighted the ability of $S$. cerevisiae to cope with very low $\mathrm{pH}$ conditions and the requirement of coupling redox balance with metabolic engineering strategies. In addition to the expression of ldhA and knockout of PDC1, CYB2 and GPD1, the deletion of genes involved in NADH-consuming reactions of the cytosolic NADH dehydrogenase (NDE1 and NDE2) increased the availability of intracellular redox cofactor, leading to the production of $117 \mathrm{~g} / \mathrm{L}$ of LA (Lee et al., 2015).

The positive correlation between lignocellulosic sugars and the production of organic acids can be observed in the engineering of lignocellulosic sugar-consuming yeast to express a LDH gene. As abovementioned, $S$. cerevisiae can produce LA by the introduction of heterologous $\mathrm{LDH}$. However, the three native pyruvate decarboxylase genes (PDC1, PDC5, and PDC6), which are involved in the conversion of pyruvate into acetaldehyde (Hohmann, 1991), compete with this heterologous pathway for pyruvate, leading to higher production of ethanol than LA (Colombié et al., 2003). Therefore, as seen above, a common strategy to overcome this limitation is the deletion of these genes, which may result in a deficit of $\mathrm{C} 2$ compounds necessary for yeast growth (van Maris et al., 2004). Nevertheless, the integration of lactate dehydrogenase gene, $l d h A$, into a $S$. cerevisiae strain previously engineered for xylose consumption led to a clear favouring of LA production over ethanol production ( $<0.01 \mathrm{~g}$ ethanol $/ \mathrm{g}$ xylose). This strain produced $49.1 \mathrm{~g} / \mathrm{L}$ of LA with a yield of $0.60 \mathrm{~g} / \mathrm{g}$, with xylose as sole carbon source and without any of the PDC genes deleted (Turner et al., 2015). Contrarily, when glucose was the only carbon source, ethanol yield $(0.31 \mathrm{~g} / \mathrm{g}$ of glucose) was higher than LA yield $(0.22 \mathrm{~g} / \mathrm{g}$ of glucose). The authors named this phenomenon as substrate-dependent product formation. The putative molecular mechanisms associated with this phenomenon are still unclear, but some possible explanations have arisen. One is that the slower uptake of xylose compared with glucose uptake leads to a lower intracellular accumulation of pyruvate, which in turn allows for a rapid conversion of pyruvate into LA by lactate dehydrogenase before the pyruvate concentration is high enough for the lower affinity pyruvate decarboxylase to become operative. Also, it is possible that the absence of glucose signalling when cultivated on xylose leads to weaker fluxes towards effective ethanol production, which ultimately may permit to prioritize the one-step conversion of pyruvate into LA (Turner et al., 2016). Finally, recognition of extracellular glucose by glucose sensors (such as SNF4 or RGT2) is known to lead to the suppression of the JEN1 gene, coding for a LA permease, which is otherwise induced when non-fermentable carbon sources like xylose are metabolized (Andrade and Casal, 2001; Jin et al., 2004). Given this, it is plausible to think that xylose cultivation results in the upregulation of JEN1, which may enable a fast secretion of LA from yeast cells. As LA can act as an allosteric inhibitor of lactate dehydrogenase, the removal of LA from the cytoplasm might increase the metabolic flux toward LA production (Turner et al., 2015). In a subsequent study, the expression of GH1-1 and $C D T-1$ genes, coding for a $\beta$-glucosidase and a cellodextrin transporter, respectively, enabled cellobiose consumption, which allied to xylose consumption led to a titre of $62 \mathrm{~g} / \mathrm{L}$ of LA. Contrary to a glucoseexclusive culture, a mixture of xylose/cellobiose favoured the production of LA over ethanol. When these 3 carbon sources were cultured together, with calcium carbonate neutralization, $83 \mathrm{~g} / \mathrm{L}$ of LA was achieved with a yield of $0.66 \mathrm{~g} / \mathrm{g}$ of sugar, while still producing ethanol simultaneously (Turner et al., 2016).

According to these findings, Novy et al. (2018) demonstrated that, in anaerobic fermentation, the LA yield on xylose $(0.27 \mathrm{~g} / \mathrm{g}$ of xylose) was higher than on glucose $(0.18 \mathrm{~g} / \mathrm{g}$ of glucose). Nevertheless, in aerobic conditions, xylose conversion to LA ceased completely, which suggests that oxygen conditions also play an important role in LA production. In xylose culture, the shift to microaerobic conditions $\left(\mathrm{OO}_{2} \approx 2 \%\right)$ prevented the LA metabolization observed in fully aerobic conditions, increasing the productivity and yield. This evidence suggests that xylose does not repress the respiratory response as much as glucose, as TCA cycle reactions on xylose under aerobic conditions are stimulated, keeping the pyruvate absent from the reaction catalysed by LDH.

The necessity to improve resistance to LA itself in order to increase its production has also been addressed. An RNAi-mediated genome-wide expression knock-down approach was employed in order to quickly identify potential genetic targets that would confer increased acid tolerance to $S$. cerevisiae. Among all the identified genes, the highest increase in LA tolerance (52\%) was found with the knockout of the ribosome-associated chaperone SSB1 gene. This genetic modification in a LA-producing strain resulted in the production of over $50 \mathrm{~g} / \mathrm{L}$ of LA, representing an increase of $60 \%$ when compared with the parental strain (Lee et al., 2016). Another study reported an increase of $20 \%$ in LA production by overexpressing ESBP6 gene. Despite its unclear function, this gene appears to be involved in LA adaptation response in $S$. cerevisiae, increasing the intracellular $\mathrm{pH}$ in yeast (Sugiyama et al., 2016). The heterologous expression of acid stable enzymes from acidophilic archaea Picrophilus torridus was also found to increase glycolytic flux at low intracellular $\mathrm{pH}$ conditions, leading to a $20 \%$ increase in LA titre when compared to the parental strain (Ryu et al., 2018).

A one-step generation of LA-producing strains through simultaneous insertion of $l d h L$ and disruption of PDC1 and PDC5 genes in S. cerevisiae genome via CRISPR/Cas9 was reported for one diploid industrial strain (Stovicek et al., 2015). Stemming on this technology, another study 


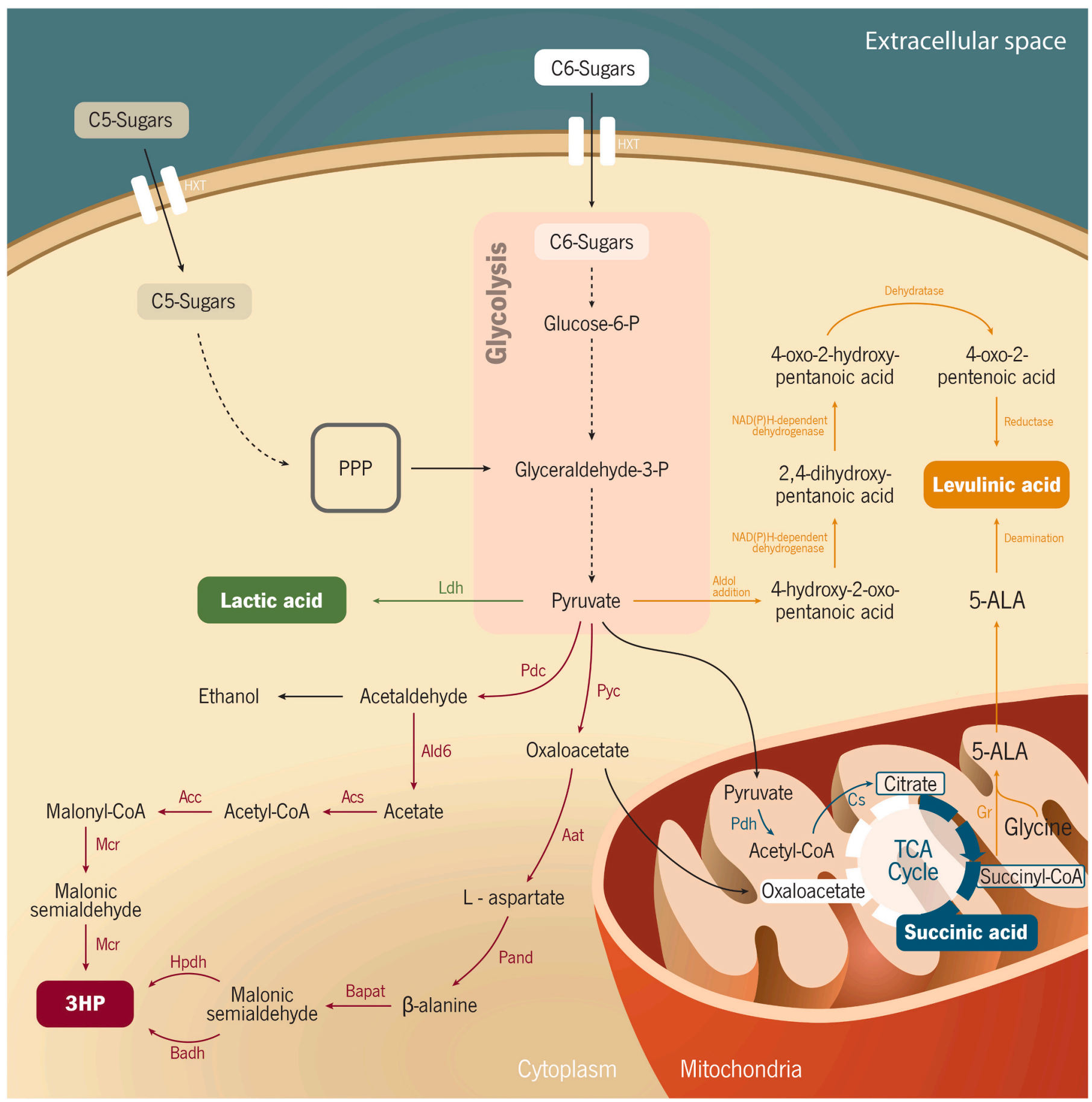

Fig. 1. Metabolic pathways for the production of organic acids in Saccharomyces cerevisiae: red arrows represent the reactions for the two main 3-hydroxypropionic acid pathways; green arrows for lactic acid pathway; orange arrows for levulinic acid pathway; blue arrows for succinic acid pathway. Dashed arrows indicate multiple step reactions. Abbreviations: Ldh, lactate dehydrogenase; Pyc, pyruvate carboxylase; Aat, aspartate transaminase; Pand, aspartate decarboxylase; Bapat, $\beta$-alanine-pyruvate transaminase; Hpdh, 3-hydroxypropionate dehydrogenase; Badh, 3-hydroxyisobutyrate dehydrogenase; Pdc, pyruvate decarboxylase; Ald6, aldehyde dehydrogenase; Acs, acetyl-CoA synthase; Acc, acetyl-CoA carboxylase; Mcr, malonyl-CoA reductase; Pdh, pyruvate dehydrogenase, Cs, citrate synthase; Gr, glutamyl-tRNA reductase. PPP, pentose phosphate pathway; Glucose-6-P, glucose-6-phosphate; Glyceraldehyde-3-P, glyceraldehyde-3-phosphate.

successfully knocked out four genes in a single step in diploid and triploid strains to increase LA titre in xylose-consuming LA-producing strains (Lian et al., 2018).

LA production from lignocellulosic biomass has been already reported, where a xylose-consuming strain was successfully engineered with a heterologous LDH. The recombinant strain produced $11.15 \mathrm{~g} / \mathrm{L}$ of LA from spent coffee grains whole slurry, obtained by acid-pretreatment (Kim et al., 2019). Another study reported LA production from lactose.
Stemming on the ability of CDT-1 transporter (CDT-1) to transport lactose into the cell, a strain expressing both CDT-1 and GH1-1 ( $\beta$-glucosidase with $\beta$-galactosidade activity) alongside $l d h A$ successfully produced LA from lactose, either purified $(23.77 \mathrm{~g} / \mathrm{L})$ or derived from dairy milk $(10.3 \mathrm{~g} / \mathrm{L})$ or cheese whey $(15.6 \mathrm{~g} / \mathrm{L})$. This is relevant for the valorisation of industry by-products such as contaminated milk or cheese whey itself (Turner et al., 2017) or even for multi-waste valorisation approaches targeting lignocellulosic residues and whey (Cunha 
et al., 2018b). Overall, LA production is a very well-established process in an industrial context, even though there is room for increasing its rates and yield. Nonetheless, the necessity of the industry for high purity LA drives the effort for continuous improvement of efficient and economically feasible methods for downstream processing (Ahmad et al., 2020).

\subsubsection{Succinic acid}

Succinic acid (SA) is a valuable platform chemical with huge potential as a building block for several products such as butanediol or nylon-type polymers (Becker et al., 2015), as well as acidity regulator in the food and beverage industry (Borodina and Nielsen, 2014). As of 2019 , SA market is valued at $\$ 185.6$ million, with a CAGR of $15.7 \%$ for the upcoming 2020-2026 period (PR Newswire, 2020). SA can be produced either by chemical or biotechnological synthesis. Several chemical processes have been developed in the past, such as electrolytic reduction of maleic acid or maleic anhydride, or paraffin oxidation and catalytic hydrogenation (Muzumdar et al., 2004; Cok et al., 2014). Due to its high conversion yield and efficiency, biotechnological production of SA is considered to be economically feasible and competitive in comparison to its petrochemical synthesis (Hermann et al., 2007). The annual manufacture of microbial-based SA in Europe and North America represents already nearly half of worldwide overall production (Kumar et al., 2020a). The bacteria E. coli (Wang et al., 2011) and Corynebacterium glutamicum (Okino et al., 2008; Litsanov et al., 2012) are the most used microorganisms as recombinant hosts for SA production, yielding concentrations of SA from glucose above $100 \mathrm{~g} / \mathrm{L}$. The yeast Yarrowia lipolytica has also been successfully used for SA production from glycerol, with a maximum reported titre of $198.2 \mathrm{~g} / \mathrm{L}$ (Li et al., 2017). Several companies, such as Biosuccinium, already commercialize microbial-based SA, using $S$. cerevisiae strains to produce SA from starch/sugar (Mancini et al., 2019).

SA is an intermediate of the tricarboxylic acid (TCA) cycle, naturally occurring in S. cerevisiae (Fig. 1). Strategies to enable SA accumulation rely on the deletion of genes encoding for succinate dehydrogenase $(\mathrm{SDH})$ subunits (SDH1, SDH2, SDH3 and $S D H 4)$, which leads to an increase in SA production in aerobic conditions by interrupting the TCA cycle and, therefore, avoiding SA depletion (Kubo et al., 2000). Raab et al. (2010) reported a production of $3.62 \mathrm{~g} / \mathrm{L}$ of SA from glucose by deleting SDH1 and SDH2 allied to the elimination of IDH1 and IDP1, both encoding for isoenzymes of isocitrate dehydrogenase. This enabled a redirection of carbon flux to the glyoxylate cycle that ultimately allowed the accumulation of SA as final product, representing a 4.8-fold increase when comparing to the wild-type strain. In another study, the production of SA was 30-fold improved, compared to the wild-type strain. The combination of directed evolution strategies with the knockout of SDH3 gene, overexpression of native ICL1 (encoding isocitrate lyase), and deletion of the genes encoding both isoenzymes encoding 3-phosphoglycerate dehydrogenase (Ser3p/Ser33p) led to the interruption of serine formation from glycolysis. L-serine is required for biomass formation, and can be alternatively synthesized from L-glycine, which is coupled to SA production through the glyoxylate pathway. By its turn, glyoxylate is produced from isocitrate, by isocitrate lyase action, producing equimolar amounts of succinate. Therefore, as biomass increases, so does the demand for L-glycine and L-serine, which ultimately leads to a SA production process coupled with biomass (Otero et al., 2013). Ito et al. (2014), in addition to the deletion of SDH1 and SDH2 genes, accomplished the elimination of ethanol biosynthesis pathways ( $A D H 1$ to $A D H 5$ genes knockout), which led to an accumulation of intracellular SA. By enhancing SA export to the outside of the cell through heterologous expression of mae1 gene (encoding a malic acid transporter), a SA yield of $2.4 \%$ (C-mol per C-mol glucose consumed) was attained.

Another study based its strategy on the deletion of PDC genes, blocking ethanol production and channelling carbon flux through the TCA cycle, allied to the knockout of FUM1 and GPD1 to avoid malate and glycerol production, respectively, and lastly expressing PYC2 to boost SA production from pyruvate. This led to the production of $12.97 \mathrm{~g} / \mathrm{L}$ of $\mathrm{SA}$, under optimal supplemental $\mathrm{CO}_{2}$ conditions in a bioreactor (Yan et al., 2014). Recently, Xiberras et al. (2020) reported the production of SA from glycerol. For full exploitation of the higher reducing power of glycerol, the authors used a previously engineered strain with the native L-glycerol 3-phosphate (L-G3P) pathway replaced by an alternative NAD-dependent DHA pathway for glycerol catabolism (Klein et al., 2016). This was followed by the (over)expression of the endogenous peroxisomal malate dehydrogenase (MDH3), which is responsible for oxaloacetate reduction, the heterologous cytosolic fumarase (fumR) from Rhizopus oryzae for conversion of malate to fumarate, and the peroxisomal fumarate reductase ( $F R D g$ ) from Trypanosoma brucei for fumarate reduction. These modifications together with the expression of the dicarboxylic acid transporter DCT-02 from Aspergillus niger resulted in a maximum SA titre of $10.7 \mathrm{~g} / \mathrm{L}$ and a yield of $0.22 \mathrm{~g} / \mathrm{g}$ of glycerol in shake batch culture. The shift to an exclusive microbial-based SA production is still pendent on further improvements focusing on economic competitiveness against the petrochemical synthesis. Process optimization and use of low-cost raw materials (Kumar et al., 2020a) such as lignocellulosic materials or crude glycerol can help in attaining this goal, and $S$. cerevisiae can indeed play an important role in this field. Nonetheless, the titres reported so far are still very low when compared to the production levels attained with several other microorganisms, and additional investigation of metabolic mechanisms and reactions should be an immediate priority.

\subsubsection{Hydroxypropionic acid}

3-Hydroxypropionic acid (3HP) is a carboxylic acid with enormous market potential as a precursor for acrylic acid (Becker et al., 2015). 3HP comprises two functional groups, a carboxyl group and a $\beta$-hydroxyl group, showing potential as a versatile platform to produce a vast assortment of high value-added compounds. Several compounds can be produced from 3HP such as 1,3-propanediol, acrylic acid, acrylamide, propiolactone, malonic acid, among others (Matsakas et al., 2018), which in turn have a wide range of applications in manufacturing adhesives, polymers, fibres, cleaning agents and resins. Efforts for $3 \mathrm{HP}$ production rely mainly on glycerol and glucose, with the first one being the most straightforward approach by only requiring the sole activities of glycerol dehydratase and aldehyde dehydrogenase. Stemming on this glycerol-based approach, several microorganisms have been used as hosts for 3HP production, from where E. coli (Chu et al., 2015) and Klebsiella pneumoniae stand out as the more promising in this field, with the latter having the highest titre reported (83.8 g/L; Li et al., 2016). Regarding its production from glucose, Chen et al. (2017a) reported the highest titre to date $(62.6 \mathrm{~g} / \mathrm{L})$ using a recombinant $C$. glutamicum. There are many different pathways described to produce 3HP from glucose, with research studies on $S$. cerevisiae $3 \mathrm{HP}$ production focusing mainly on malonyl-CoA or $\beta$-alanine pathways (Fig. 1) (Chen and Nielsen, 2016). The malonyl-CoA pathway is based on the expression of heterologous malonyl-CoA reductase (MCR). Chen et al. (2014) increased acetyl-CoA accumulation by blocking its consumption and increased NADPH formation by multiple gene overexpression and MLS1 deletion, simultaneously with the overexpression of ACC1 catalysing acetyl-CoA to malonyl-CoA, which led to the production of $463 \mathrm{mg} / \mathrm{L}$ of $3 \mathrm{HP}$ from glucose. Another study focused on the downregulation of lipid synthesis combined with the study of inositol and choline effect, resulted in 477 $\mathrm{mg} / \mathrm{L}$ of 3HP (Chen et al., 2017b). Intracellular malonyl-CoA pool is critical for the production of 3HP via the malonyl-CoA pathway, as shown in a study that reports that acetyl-CoA carboxylase, crucial for malonyl-CoA synthesis, can be upregulated by eliminating phosphorylation inhibition, which improved 3HP production by 2.2-fold (Shi et al., 2014). Kildegaard et al. (2016) showed that integration of multiple copies of MCR and phosphorylation-deficient acetyl-CoA carboxylase ACC1 ${ }^{\text {S659A,S1157A }}$ genes improved 3HP titre by 5 -fold, when compared with single integration, despite a reduced growth rate of the strains 
expressing the malonyl-CoA route. After optimization of acetyl-CoA supply and NADPH formation, the resultant strain was able to produce $9.8 \mathrm{~g} / \mathrm{L}$ of $3 \mathrm{HP}$ in fed-batch cultivation at $\mathrm{pH} 5$.

The influence of gene expression levels has also been a subject of study. Based on a hierarchical dynamic control system around malonylCoA, a novel malonyl-CoA biosensor was used to activate expression of a heterologous malonyl-CoA pathway from Chloroflexus aurantiacus. This strategy led to a 10-fold increase in 3HP production (David et al., 2016). The effect of different promoters induced in glucose-limiting conditions was also assessed, where $I L C 1$ promoter was found to improve the titre of $3 \mathrm{HP}$ by $70 \%$ in comparison to PGK1 promoter (Maury et al., 2018).

Regarding the $\beta$-alanine pathway, the (over)expression of several native and heterologous genes coupled with the production of a novel $\beta$-alanine-pyruvate aminotransferase discovered in Bacillus cereus, resulted in $13.7 \mathrm{~g} / \mathrm{L}$ of $3 \mathrm{HP}$ in fed-batch conditions under low $\mathrm{pH}$ (Borodina et al., 2015). This strain was later on used in a couple of different studies focusing on the (1) development of a malonyl-CoA biosensor to control its intracellular concentration, which increased 3HP titre from glucose by $120 \%$ (Li et al., 2015, 2) process optimization in small-scale chemostat cultivation, yielding $15.9 \% \mathrm{C}-\mathrm{mol}$ and $0.45 \mathrm{~g} / \mathrm{g}$ of cell dry weight under carbon-limiting conditions, using also glucose as substrate (Lis et al., 2019).

Production of 3HP from xylose was also reported, either through malonyl-CoA or $\beta$-alanine pathways (using two different approaches, a NADH-dependent $\beta$-alanine pathway and a NADPH-dependent $\beta$-alanine pathway). By introducing the three pathways separately into a previously engineered xylose-consuming $S$. cerevisiae strain, it was observed that the malonyl-CoA pathway was the better choice, when using glucose as substrate. Conversely, the NADPH-dependent $\beta$-alanine pathway yielded highest 3HP production from xylose, resulting in 7.37 $\mathrm{g} / \mathrm{L}$ of $3 \mathrm{HP}$ in $120 \mathrm{~h}$ under fed-batch cultivation using xylose as sole carbon source (Kildegaard et al., 2015). Despite being relatively low when compared with the overall panorama of $3 \mathrm{HP}$ production, these values are very promising in the biorefinery context, as glucose and xylose are two of the major sugars found in lignocellulosic biomass.

A study showed a highly efficient method based on the CRISPR/Cas9 technology where an industrial diploid $S$. cerevisiae strain was engineered for expression of $M C R$ and ACC1 $1^{\text {S659A,S1157A }}$ coupled to the overexpression of the cytoplasmic pyruvate dehydrogenase (PDH) complex, leading to an improvement of $23 \%$ in $3 \mathrm{HP}$ production over the strain without the insertion of the PDH complex (Jessop-Fabre et al., 2016). Stemmed on the ability of dCas9-based strategies for fineregulation of gene expression, Ferreira et al. (2019) reported novel fine-tuning setups that improved endogenous metabolic fluxes toward increasing levels of acetyl-CoA and malonyl-CoA. The highest boost in $3 \mathrm{HP}$ production was attained by targeting the gene encoding adenylate kinase 1, $A D K 1$, resulting in an improvement of $36 \%$ when compared to the control strain where no guide RNA was added. Even though the already reported approaches led to titres above $10 \mathrm{~g} / \mathrm{L}$ of $3 \mathrm{HP}$ in yeast, this is still distant from the over $100 \mathrm{~g} / \mathrm{L}$ believed to be commercially viable (Kumar et al., 2013). Nevertheless, ongoing optimization of the known metabolic pathways allied to the arisen of novel and more efficient separation techniques can aid to increase 3HP titres (Ji et al., 2018), making its microbial-based production feasible at an industrial scale in a near-future.

\subsubsection{Levulinic acid}

Levulinic acid is a linear five-carbon keto acid, being considered a valuable commodity chemical. Levulinic acid-derived chemicals are used in a wide range of industries like solvents, electronics, textiles and pharmaceutical products, among many others (Signoretto et al., 2019). Global market size of levulinic acid is around $\$ 26.3$ million as of 2018 , expecting to reach $\$ 34.5$ million by 2024 , representing a CAGR of $4.9 \%$ in the forecast period between 2019 and 2024 (Kumar et al., 2020b). The main worldwide producer of levulinic acid is GF Biochemicals Ltd., which developed a novel technology for production, recovery and purification of this acid (Kumar et al., 2020b). Levulinic acid can be produced by chemical conversion processes from diverse renewable raw materials, like starch-rich waste and lignocellulosic biomass, or precursors such as HMF and furfural (Morone et al., 2015). The most common approach is the dehydration of biomass or carbohydrates through an acid treatment (Cha and Um, 2020). So far, to the best of our knowledge, no studies have reported biological production of levulinic acid. The same does not apply to its derivative 5-aminolevulinic acid (5ALA), an industrial fine chemical with important physiological functions in humans and other organisms, such as acting as a substrate for heme biosynthesis (Hara et al., 2019). 5-ALA can be chemically synthesized, but is also produced biologically in animal cells, photosynthetic bacteria or algae, among others. 5-ALA can then be converted into levulinic acid by deamination (Morone et al., 2015). Its production has been conveyed since several decades ago in a vast range of microorganisms like Chlorella sp. (Beale, 1970), Rhodobacter sphaeroides (Sasaki et al., 2002) or recombinant E. coli (van der Werf and Zeikus, 1996), among others. More recently, Hara et al. (2019) have published the production of 5ALA using an engineered $S$. cerevisiae strain, by overexpressing HEM1 and ACO2, encoding for 5-ALA synthetase and aconitase, respectively, resulting in the production of $1.36 \mathrm{mg} / \mathrm{L}$ of 5-ALA. To date, the only report on levulinic acid production via metabolic engineering is a patented six-step alternative single pathway, from C5- or C6-sugars through pyruvate (Fig. 1), with potential application in a wide range of microorganisms such as Pseudomonas sp., Escherichia coli, Saccharomyces sp., Pichia $s p$. or Bacillus sp., in addition to cell-free systems (Zanghellini, 2012). Altogether, these findings may help to establish $S$. cerevisiae as a viable host for an environmental-friendly process for levulinic acid production.

\subsection{Sugar alcohols: sorbitol and xylitol}

\subsubsection{Sorbitol}

Sorbitol, also known as D-glucitol, is the sugar alcohol with the largest volume market (estimated to be 1.8 million tonnes/year) (De Jong et al., 2020). Due to the sweetness profile similar to sucrose and low caloric content, it is mainly used as a sweetener in a wide range of food products, being also used in pharmaceutical and nutraceutical formulations (Isikgor and Becer, 2015; Zhang et al., 2013). Additionally, sorbitol can be used for the industrial production of ascorbic acid (vitamin $\mathrm{C}$ ) and for the synthesis of functional derivatives, such as glycerol, propylene glycol, ethylene glycol, ethanol and methanol, which can be further used in the manufacture of other attractive compounds (Isikgor and Becer, 2015). Sorbitol is currently manufactured on a large scale by several companies through the chemical hydrogenation of glucose obtained from the enzymatic hydrolysis of food crops (corn, cassava and wheat) (Rosales-Calderon and Arantes, 2019). Although the chemical process is well established and fully implemented, the biotechnological production of sorbitol has also been investigated. Some studies focusing on Zymomonas mobilis and Lactobacillus plantarum reported the production of sorbitol from fructose and glucose, respectively (Silveira and Jonas, 2002; Ladero et al., 2007). In S. cerevisiae, the native SOR1 gene encodes a sorbitol dehydrogenase responsible for the conversion of sorbitol to fructose (using $\mathrm{NAD}^{+}$as cofactor) that also catalyses the reverse reaction (Sarthy et al., 1994; Jain et al., 2011). Duvnjak et al. (1991a) reported the production of sorbitol and ethanol in a fructose medium using a mutant of $S$. cerevisiae (ATCC 36859) lacking hexokinase activity. Taking into account that Jerusalem artichokes contain a large amount of fructose, the authors used this substrate to produce sorbitol. The fermentation of Jerusalem artichokes juice supplemented with yeast extract resulted in $2.19 \mathrm{~g} / \mathrm{L}$ of sorbitol (Duvnjak et al., 1991b). An intergeneric protoplast fusion method was also proposed to produce sorbitol directly from Jerusalem artichokes. The stable fusant between Kluyveromyces sp. Y-85 (with high activity of inulinase that enables the use of inulin from Jerusalem artichokes) and S. cerevisiae E-15 (reported as a sorbitol high-producing strain) produced 


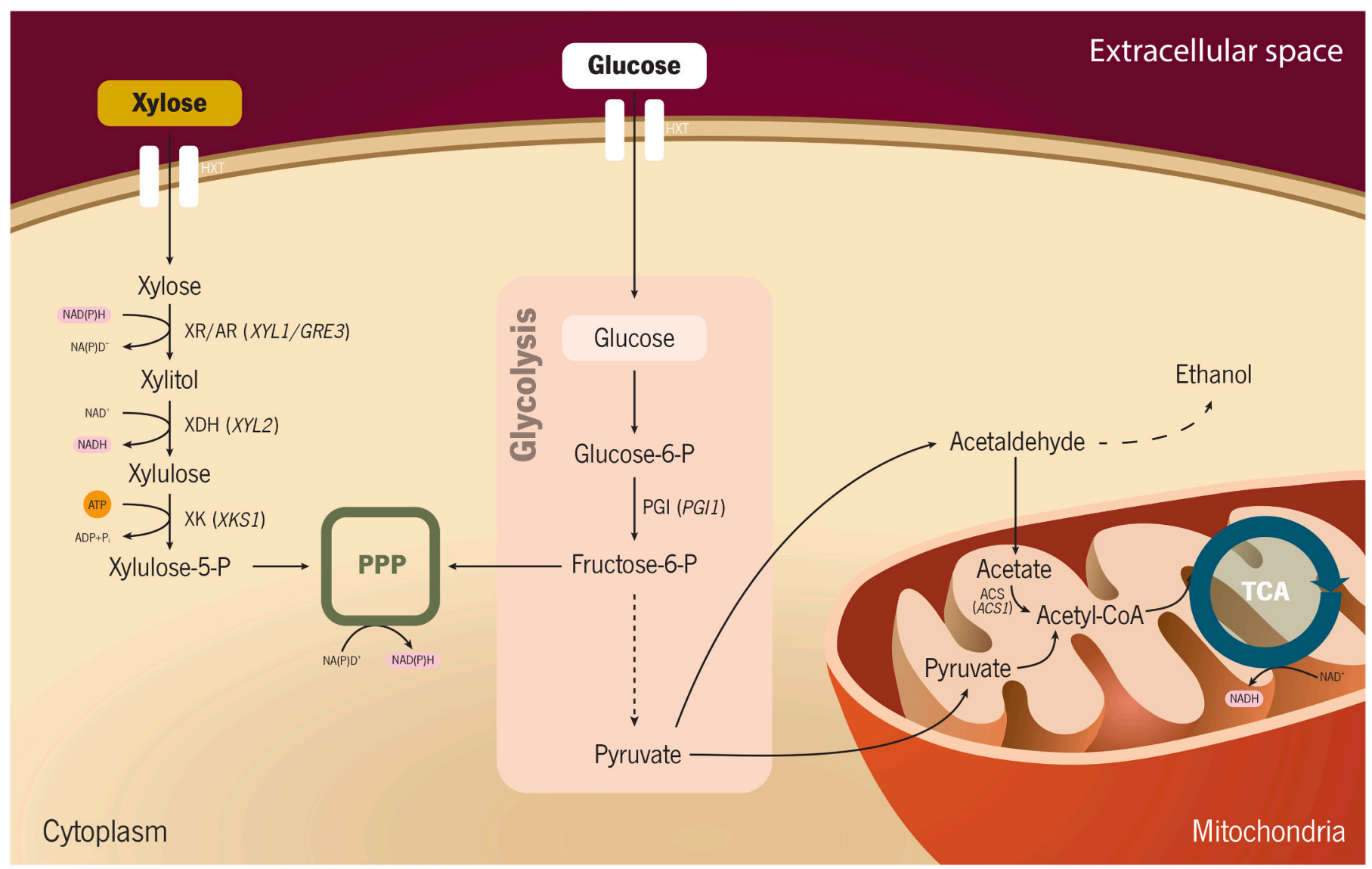

Fig. 2. Metabolic pathways involved in xylitol production by yeast and introduced genetic modifications. Dashed arrows indicate multiple step reactions. Abbreviations: XR, xylose reductase; AR, aldose reductase; XDH, xylitol dehydrogenase; XK, xylose kinase; PPP, pentose phosphate pathway; PGI, phosphoglucose isomerase.

$48.7 \mathrm{~g} / \mathrm{L}$ of sorbitol under optimal fermentation conditions (Wei et al., 2001). In a different approach, aiming to eliminate glycerol as a fermentation by-product and replace it with other metabolites, the production of sorbitol ( $4.39 \mathrm{~g} / \mathrm{L})$ was achieved by expression of the E. coli srlD gene (encoding for a sorbitol-6-phosphate dehydrogenase) in a $S$. cerevisiae strain unable to produce glycerol (gpd1 $\Delta g p d 2 \Delta$ double mutant) (Jain et al., 2011).

Presently, few biotechnological processes have been proposed for sorbitol production. In fact, the fermentative routes for the production of sorbitol cannot yet compete with the current catalytic hydrogenation process, which efficiently yields sorbitol ( $\sim 99 \%$ reaction yields) and fulfils the requirements of the food industry. However, with the introduction of the concept of sustainable production, research efforts in biomass conversion and design of microorganisms capable to efficiently ferment streams with multiple compounds are being pursued, which may lead to greening opportunities in sorbitol production.

\subsubsection{Xylitol}

Xylitol is a five-carbon sugar alcohol widely used as a low-calorie sweetener in food and beverage products (bakery, confectionery, dairy), as well as in functional foods for diabetes management. The growing concerns about adverse health impacts related with excessive sugar consumption are increasing the demand for sugar substitutes. Consequently, xylitol market is expanding and is expected to reach $\$ 1.37$ thousand million by 2025 with a price of $\$ 4000-5000$ per tonne (Hernandéz-Peréz et al., 2019). In addition, xylitol has received special attention due to its anticariogenic properties, being therefore predominantly used in chewing gum and dental care products (Janakiram et al., 2017; Salli et al., 2019). It is also used in the chemical industry as intermediate for the synthesis of ethylene and propylene glycol, lactic acid, glycerol, xylaric and xylonic acids and polymers (Hernandéz-Peréz et al., 2019; Isikgor and Becer, 2015; Werpy and Petersen, 2004). This platform chemical can be obtained from xylose in a single-step bioconversion and represents an example of a promising value-added chemical produced from lignocellulosic biomass. In fact, the use of xylose extracted from corn cob feedstocks for xylitol production is already industrially implemented (De Jong et al., 2020). The production process involves the acid pretreatment of lignocellulosic biomass for xylan decomposition into monomeric xylose. The resulting xylose-enriched hydrolysates are purified using exchange chromatography and activated carbon prior to the catalytic hydrogenation of xylose to xylitol, since the chemical conversion requires pure xylose (Dasgupta et al., 2017). This production process, in spite of using a renewable raw material, is far from being environmentally friendly and requires considerable energy and materials consumption (Rosales-Calderon and Arantes, 2019). Bioconversion approaches based on whole-cell biocatalysts aim to reduce the chemical inputs and have the inherent advantage of directly using hemicellulose hydrolysates, since microbial conversion does not require isolated and purified xylose, eliminating the need for the costly purification steps prior to xylose reduction (Bozell and Petersen, 2010).

Considerable research efforts have focused on native xylose-utilizing yeasts (Candida, Debaromyces, Kluveromyces, Pichia sp). Xylose assimilation capacity is conferred by the oxidoreductase pathway in which two enzymes, xylose reductase (XR) and xylitol dehydrogenase (XDH), are used to convert D-xylose to D-xylulose (Fig. 2). Xylitol is the first intermediate of this pathway and its accumulation is caused by the cofactor imbalance between xylose reductase (XR) and xylose 
Table 2

Metabolic engineering strategies for xylitol production in S. cerevisiae

\begin{tabular}{|c|c|c|c|c|c|c|}
\hline \multirow[t]{2}{*}{ Strain } & \multirow[t]{2}{*}{ Genetic modification } & \multirow{2}{*}{$\begin{array}{l}\text { Substrate/ cultivation } \\
\text { strategy }\end{array}$} & \multicolumn{3}{|l|}{ Xylitol } & \multirow[t]{2}{*}{ Reference } \\
\hline & & & $\begin{array}{l}\text { Titre } \\
\text { g/L }\end{array}$ & $\begin{array}{l}\text { Productivity } \\
\mathrm{g} / \mathrm{L} \cdot \mathrm{h}\end{array}$ & $\begin{array}{l}\text { Yield } \\
\mathrm{g} / \mathrm{g}\end{array}$ & \\
\hline GPY55-15B $\alpha+$ pMA91 & $\begin{array}{l}\text { Expression of XYL1 (coding for xylose reductase) } \\
\text { from Scheffersomyces stipitis }\end{array}$ & Xylose + glucose, Batch & 19 & NR & $\begin{array}{l}> \\
0.95\end{array}$ & Hallborn et al., 1991 \\
\hline H475 & & $\begin{array}{l}\text { Xylose + glucose, ethanol, } \\
\text { acetate and glycerol, Batch }\end{array}$ & NR & NR & $\approx 1$ & Hallborn et al., 1994 \\
\hline EH13.15:pY2XR & & $\begin{array}{l}\text { Xylose + glucose, Fed- } \\
\text { batch }\end{array}$ & 105 & 1.69 & $\begin{array}{l}> \\
0.95\end{array}$ & Lee et al., 2000 \\
\hline \multirow[t]{2}{*}{ BJ3505/8XR } & & $\begin{array}{l}\text { Xylose }+ \text { glucose, Fed- } \\
\text { batch }\end{array}$ & 78 & 1.1 & 0.9 & Chung et al., 2002 \\
\hline & & $\begin{array}{l}\text { Xylose }+ \text { glucose, Fed- } \\
\text { batch and cell-recycling } \\
\text { fermentation }\end{array}$ & 116 & 2.34 & 0.9 & Bae et al., 2004 \\
\hline Y294:pRG16 & Expression of XYL1 from Candida shehatae & Xylose + glucose, Batch & 15 & NR & 0.86 & Govinden et al., 2001 \\
\hline DXXA & $\begin{array}{l}\text { XYL1 gene from Scheffersomyces stipitis; AraE } \\
\text { (arabinose: } \mathrm{H}^{+} \text {symporter) from Bacillus subtilis }\end{array}$ & $\begin{array}{l}\text { Xylose }+ \text { glucose, Fed- } \\
\text { batch }\end{array}$ & 178 & 2.47 & $\approx 1$ & Kim et al., 2017 \\
\hline D-10-BT & $\begin{array}{l}\text { XYL1 (xylose reductase) from Scheffersomyces } \\
\text { Stipitis; CDT-1 (cellodextrin transporter); GDH1-1 } \\
\text { (ß-glucosidase) from the Neurospora crassa }\end{array}$ & $\begin{array}{l}\text { Xylose }+ \text { cellobiose, Fed- } \\
\text { batch }\end{array}$ & 93 & 1.50 & 0.98 & Oh et al., 2013 \\
\hline SR8\#22 & $\begin{array}{l}\text { Evolved strain mutated in GLK1 (glucokinase), } \\
\text { HXK1 (hexokinase 1) and HXK2 (hexokinase 2) } \\
\text { genes, expressing XYL (xylose reductase) }\end{array}$ & & 21 & NR & $\approx 1$ & Lane et al., 2018 \\
\hline \multirow[t]{3}{*}{ PE-2-GRE3 } & GRE3 (endogenous aldose reductase) & $\begin{array}{l}\text { Xylose }+ \text { glucose, Fed- } \\
\text { batch }\end{array}$ & 148.5 & 1.16 & 0.95 & Baptista et al., 2018 \\
\hline & & $\begin{array}{l}\text { Corn cob whole slurry, } \\
\text { Simultaneous } \\
\text { Saccharification and } \\
\text { fermentation }\end{array}$ & 30 & 0.54 & 0.95 & \\
\hline & & $\begin{array}{l}\text { Hardwood xylan, } \\
\text { Simultaneous } \\
\text { Saccharification and } \\
\text { Fermentation }\end{array}$ & 24 & 0.38 & $\approx 1$ & Romaní et al., 2020 \\
\hline \multirow[t]{2}{*}{ ScpGT } & $\begin{array}{l}\text { GRE3 (endogenous aldose reductase) and SUT1 } \\
\text { (xylose specific transporter) }\end{array}$ & $\begin{array}{l}\text { Xylose + glucose, Fed- } \\
\text { batch }\end{array}$ & 21 & 0.34 & $\approx 1$ & Kogje and Ghosalkar, 2016 \\
\hline & & $\begin{array}{l}\text { Corn cob hydrolysate }+ \\
\text { glucose, Fed-batch }\end{array}$ & 22 & NR & $\approx 1$ & \\
\hline DWM-ZWF1-ACS1 & $\begin{array}{l}\text { XYL1 (xylose reductase, NADPH-dependent) from } \\
\text { Scheffersomyces stipitis; } \triangle X Y L \text { (mutant xylose } \\
\text { reductase, NADH-preferring); ZWF1 (glucose-6- } \\
\text { phosphate dehydrogenase); ACS1 (acetyl-CoA } \\
\text { synthetase) }\end{array}$ & $\begin{array}{l}\text { Xylose + glucose, Fed- } \\
\text { batch }\end{array}$ & 196 & 4.27 & $\approx 1$ & Jo et al., 2015 \\
\hline D-10-BT & $\begin{array}{l}\text { XYL1 (xylose reductase) from Scheffersomyces } \\
\text { stipitis; CDT1 (cellodextrin transporter); GDH11(ß- } \\
\text { glucosidase) from the Neurospora crassa }\end{array}$ & $\begin{array}{l}\text { Xylose }+ \text { cellobiose, Fed- } \\
\text { batch }\end{array}$ & 93 & 1.50 & 0.98 & Oh et al., 2013 \\
\hline XP-RTK & $\begin{array}{l}\text { XYL1 (xylose reductase) from Scheffersomyces } \\
\text { stipitis, Candida Tropicalis, Neurospora crassa and } \\
\text { SUT1 (xylose specific transporter) }\end{array}$ & $\begin{array}{l}\text { Glycerol, corn cob } \\
\text { hydrolysate Fed-batch }\end{array}$ & 47 & 0.37 & $\approx 1$ & Kogje and Ghosalkar, 2017 \\
\hline \multirow[t]{2}{*}{$\begin{array}{l}\text { YPH499-XR-BGL-XYL- } \\
\text { XYN }\end{array}$} & $\begin{array}{l}\text { XYL1 (xylose reductase) from Scheffersomyces } \\
\text { stipitis, BGL ( } \beta \text {-glucosidase) from Aspergillus }\end{array}$ & $\begin{array}{l}\text { Rice straw hydrolysate, } \\
\text { CBP }\end{array}$ & 6 & NR & $\approx 1$ & Guirimand et al., 2016 \\
\hline & $\begin{array}{l}\text { aculeatus, XylA ( } \beta \text {-xylosidase) from Aspergillus } \\
\text { oryzae and XYN (endoxylanase II) from Trichoderma } \\
\text { reesei }\end{array}$ & $\begin{array}{l}\text { Rice straw hydrolysate } \\
\text { (membrane-filtrated), CBP }\end{array}$ & 38 & NR & & \\
\hline \multirow[t]{2}{*}{$\begin{array}{l}\text { YPH499-XR-BGL-XYLsss- } \\
\text { XYNsss }\end{array}$} & $\begin{array}{l}X Y L 1 \text { (xylose reductase) from Scheffersomyces } \\
\text { stipitis, } B G L \text { ( } \beta \text {-glucosidase) from Aspergillus }\end{array}$ & $\begin{array}{l}\text { Rice straw hydrolysate, } \\
\text { CBP }\end{array}$ & 7 & NR & $\approx 1$ & Guirimand et al., 2019a \\
\hline & $\begin{array}{l}\text { aculeatus, XylA ( } \beta \text {-xylosidase) from Aspergillus } \\
\text { oryzae and XYN (endoxylanase II) from } \\
\text { Trichoderma reesei, SED1 promoter, secretion } \\
\text { signal and anchoring domain }\end{array}$ & Kraft pulp, CBP & 4 & NR & & \\
\hline
\end{tabular}

dehydrogenase (XDH) enzymes. XR presents dual cofactor dependence but uses NADPH over NADH, whereas XDH is $\mathrm{NAD}^{+}$dependent. The differences in cofactor specificity in the $\mathrm{XR}$ and $\mathrm{XDH}$ reactions and the generation of NADPH by the pentose phosphate pathway (PPP) limit the availability of $\mathrm{NAD}^{+}$for the oxidation of xylitol to xylulose, resulting in xylitol secretion (Kötter and Ciriacy, 1993; Quehenberger et al., 2019). Among different xylose-utilizing yeasts, Candida species present the best xylitol production capacity (Barbosa et al., 1988; Dasgupta et al., 2017) and some process and metabolic engineering approaches have already proven to be successful for enhancing overall titres and productivities (Kim et al., 2004; Ko et al., 2006; Kwon et al., 2006). However, xylitol yields are limited by the use of xylose as carbon source for cell growth and maintenance energy. Given this context, the use of $S$. cerevisiae, which is naturally incapable of metabolizing xylose, is an appealing approach to enhance xylitol yields. The expression of genes coding for enzymes with XR activity allows the direction of xylose flux only for bioconversion and the xylitol produced is not further oxidized to xylulose and metabolized by this yeast. Consequently, engineered strains require a co-substrate for cell growth and metabolism but also to regenerate cofactors, essential for the NAD(P)H-dependent XR enzyme catalysis.

Initial attempts to produce xylitol in $S$. cerevisiae relied on the 
expression of XYL1 gene from the xylose-fermenting Scheffersomyces stipitis (formerly known as Pichia stipitis) coding for XR, which increased the yields near to the theoretical maximum ( $1 \mathrm{~g}$ of xylitol per gram of xylose) (Hallborn et al., 1991). The recombinant $S$. cerevisiae expressing $X Y L 1$ gene was also evaluated for xylitol production using different cosubstrates (glucose, ethanol, acetic acid and glycerol) and only glucose and ethanol were efficiently used (Hallborn et al., 1994). Similarly, the use of glucose improved the xylitol production by the recombinant $S$. cerevisiae expressing the XYL1 gene from Candida shahatae, in comparison with the results obtained using galactose and maltose as cosubstrate (Govinden et al., 2001). Nevertheless, the use of glucose as a co-substrate inhibits the transport of xylose into the cells (Subtil and Boles, 2012) decreasing xylitol productivity. A commonly used strategy for improving the xylose uptake in the presence of glucose is using a high molar ratio of xylose to glucose during the bioconversion phase. This glucose-limited fed-batch fermentation strategy has already proven to be successful for cofactor regeneration and to generate maintenance energy without glucose repression, resulting in high productivities and yields of xylitol (Table 2) (Bae et al., 2004; Chung et al., 2002; Lee et al., 2000). Another approach to bypass glucose repression and improve xylose transport relied on the expression of the B. subtilis araE gene coding for an arabinose: $\mathrm{H}^{+}$symporter, which has been previously proven to enhance xylose transport capacity in S. cerevisiae (Wang et al., 2013). The expression of araE together with the expression of XYL1 gene from $S$. stipitis, increased the xylitol productivity to $2.47 \mathrm{~g} / \mathrm{L} \cdot \mathrm{h}$ (Kim et al., 2017). Alternatively, Oh et al. (2013) efficiently produced xylitol without glucose repression through the utilization of cellobiose, a dimer of glucose. For this, a recombinant $S$. cerevisiae strain expressing a xylose reductase from $S$. stipitis was further engineered for cellobiose utilization by the expression of the CDT-1 and GH1-1 genes (from the filamentous fungus Neurospora crassa) coding for a cellodextrin transporter and intracellular B-glucosidase, respectively. The resulting strain showed cellobiose and xylose co-consumption and higher xylitol productivity, compared to sequential utilization of glucose and xylose (Oh et al., 2013). More recently, adaptive evolution followed by genome sequencing of the evolved strains coupled with reverse engineering strategies showed that reduced glucose phosphorylation rates led to simultaneous glucose and xylose utilization, improving the xylitol production (Lane et al., 2018).

In addition, some research efforts aimed to improve the availability of reduced cofactors for XR activity, which is an important controlling factor for xylitol production. To understand the role of different enzymes and cofactors preference, an industrial $S$. cerevisiae was engineered to produce a wild-type XR (NADPH-preferable) and a mutant XR (NADHpreferable) from $S$. stipitis, and also to overproduce the endogenous aldose reductase (NADPH-dependent) encoded by the GRE3 gene. The strains producing enzymes with NADPH preference showed an improved xylitol production using glucose as co-substrate, and the GRE3-overexpressing strain was able to produce $148.5 \mathrm{~g} / \mathrm{L}$ of xylitol with a $0.95 \mathrm{~g} / \mathrm{g}$ yield (Baptista et al., 2018). Also, the overexpression of the GRE3 gene resulted in higher xylitol titre and productivity over the expression of the XR encoding gene from S. stipitis, C. tropicalis or $N$. crassa (Kogje and Ghosalkar, 2016). As aforementioned, XR enzymes show a preference for NADPH over NADH and the main source of NADPH in yeast cells is the oxidative PPP. To overcome the preference for NADPH and allow the simultaneous utilization of NADPH and NADH cofactors, the co-expression of wild and mutant S. stipitis XYL1 genes enhanced the xylitol yield and productivity. This strain was further engineered to increase the intracellular concentrations of NADPH and NADH cofactors by the overexpression of both ZWF1 and ACS1 genes encoding for glucose-6-phosphate dehydrogenase (G6PDH) and acetyl$\mathrm{CoA}$ synthetase. The overproduction of the G6PDH increases the flux through PPP, responsible for NADPH production, and acetyl-CoA synthetase can contribute for cofactor regeneration since it is responsible for the conversion of acetate to acetyl-CoA, which is further metabolized in the TCA cycle, generating NADH. This engineered strain produced
$196.2 \mathrm{~g} / \mathrm{L}$ of xylitol with remarkable productivity of $4.27 \mathrm{~g} / \mathrm{L} \cdot \mathrm{h}$ (Jo et al., 2015). Another metabolic engineering approach to further increase the NADPH availability focused on the redirection of the carbon flux to the PPP, limiting the carbon flux into glycolysis. The downregulation of the PGI1 gene, coding for phosphoglucose isomerase (PGI) reduces the conversion of glucose-6-phosphate to fructose-6-phosphate in glycolysis first step, resulting in glucose-6-phosphate accumulation, which can be used by G6PDH in the PPP. The reduction of PGI activity alone was not successful, except with the simultaneous overexpression of the ZWF1 gene that improved the xylitol productivity by 1.9 -fold when compared with the parental strain expressing only the XYL1 gene (Oh et al., 2007).

Much progress has been made in the production of xylitol from lignocellulosic-derived xylose. Kogje and Ghosalkar (2016) engineered $S$. cerevisiae to produce xylitol from a non-detoxified corn cob hydrolysate supplemented with synthetic glucose in fed-batch mode. The recombinant ScpGT strain expressing the SUT1 gene, coding for a specific xylose transporter and overexpressing the GRE3 gene produced $22.4 \mathrm{~g} / \mathrm{L}$ of xylitol. The dilution of the hemicellulosic hydrolysate decreased the xylose concentration from $65 \mathrm{~g} / \mathrm{L}$ to $40 \mathrm{~g} / \mathrm{L}$ enabling also the mitigation of negative effects caused by the presence of lignocellulose-derived inhibitors (Kogje and Ghosalkar, 2016). The same authors expressed both GRE3 and SUT1 genes in an industrial strain to produce xylitol from a detoxified corn cob hydrolysate, using glycerol as co-substrate. The recombinant $S$. cerevisiae XP-RTK efficiently produced $47 \mathrm{~g} / \mathrm{L}$ of xylitol with a maximal productivity of $0.37 \mathrm{~g} / \mathrm{L} \cdot \mathrm{h}$ (Kogje and Ghosalkar, 2017). In fact, the bioconversion process might profit from the replacement of glucose by glycerol, which prevents catabolite repression and ethanol fermentation, favouring the biomass production. More recently, Baptista et al. (2018) developed an integrated process to produce xylitol through the valorisation of both cellulose and hemicellulose fractions of corn cob. The industrial $S$. cerevisiae PE-2 strain, naturally prone to xylitol accumulation (Romaní et al., 2015) and presenting a suitable background to cope with the presence of lignocellulosic-derived inhibitors (Pereira et al., 2014) was engineered by overexpression of the GRE3 gene. The corn cob whole-slurry, liquid (hemicellulosic hydrolysate) and solid fractions obtained from the corn cob autohydrolysis pretreatment, were used in a Simultaneous Saccharification and Fermentation (SSF) process. The glucan-enriched solid phase was efficiently hydrolysed by an enzymatic cocktail, providing glucose for cell growth and metabolism during the bioconversion of xylose (from the non-detoxified hydrolysate) into xylitol. This sustainability-based approach resulted in $29.6 \mathrm{~g} / \mathrm{L}$ of xylitol with a maximal productivity of $0.54 \mathrm{~g} / \mathrm{L} \cdot \mathrm{h}$ and demonstrated the feasibility of using whole slurry corn cob for xylitol production (Baptista et al., 2018). In addition, xylitol production through SSF was optimized using different enzyme and substrate loadings, achieving a maximum concentration of $47 \mathrm{~g} / \mathrm{L}$ (Baptista et al., 2020). The same robust recombinant yeast strain was exploited for SSF of hardwood xylan into xylitol using aqueous solutions of deep eutectic systems as reaction media, attaining $23.7 \mathrm{~g} / \mathrm{L}$ xylitol in an one-step process (Romaní et al., 2020). Cell surface engineering of $S$. cerevisiae has been proposed to produce xylitol directly from pretreated lignocellulosic biomass. Guirimand et al. (2016) engineered a S. cerevisiae strain to express $X Y L 1$ from $S$. stipitis and co-display three different hydrolases on its cell surface: $\beta$-glucosidase (from Aspergillus aculeatus), xylosidase (from Aspergillus oryzae) and xylanase (from Trichoderma reesei). For the cell surface attachment, the target proteins were fused to the anchoring domain of yeast cell wall proteins, SED1 or SAG1. The recombinant strain produced $5.8 \mathrm{~g} / \mathrm{L}$ of xylitol directly from the xylooligosaccharidesenriched liquid fraction of pretreated rice straw, representing $79.5 \%$ of the theoretical yield from the xylose contained in the hydrolysate. To improve xylitol titre, the rice straw hydrolysate was submitted to a membrane separation step (nanofiltration) to increase xylose concentration that also removed fermentation inhibitors, resulting in the production of $37.9 \mathrm{~g} / \mathrm{L}$ of xylitol. Nevertheless, both rice straw hydrolysates (unfiltered and membrane separated) showed an incomplete xylose conversion. In this sense, the recombinant strain was further improved 


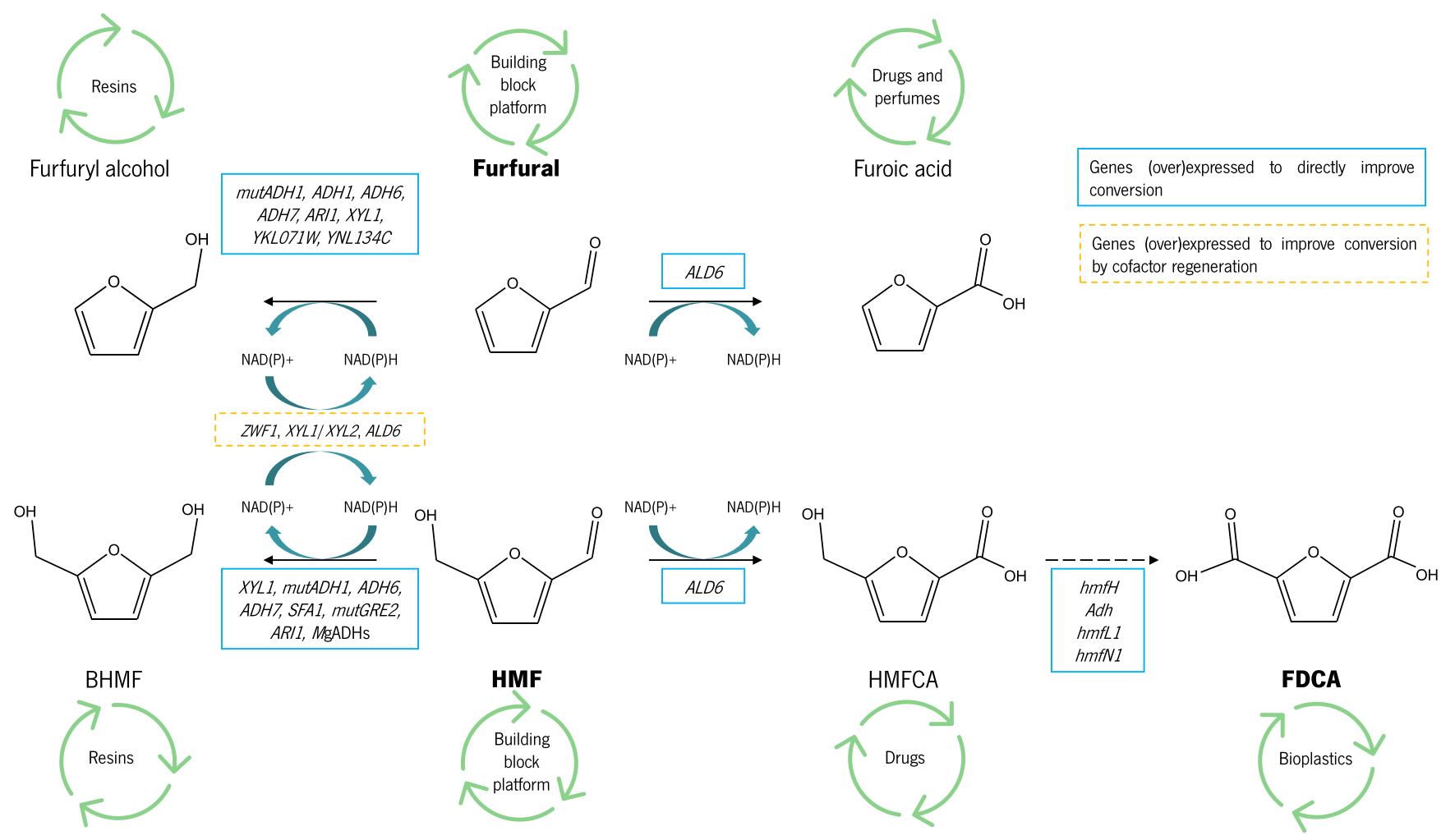

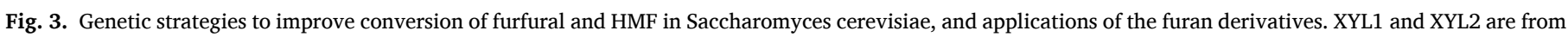

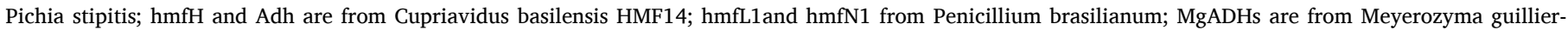

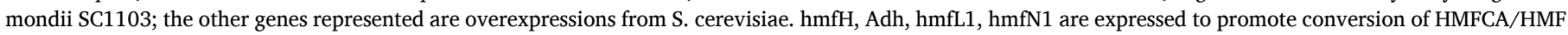
into FDCA.

in terms of promoters, secretion signal and anchoring domain sequences, achieving maximal xylitol concentrations of $6.97 \mathrm{~g} / \mathrm{L}$ and 4.2 g/L from rice straw hydrolysate and Kraft pulp residue, respectively (Guirimand et al., 2019a). Furthermore, this cell surface strategy was combined with the expression of different sugar transports to improve the xylose uptake, and the expression of MAL11 gene, encoding for a maltose transporter, resulted in a $30 \%$ increase in xylitol production (Guirimand et al., 2019b).

A considerable number of metabolic engineering strategies have been successfully applied to convert $S$. cerevisiae into an efficient xylitol producer. The recent research development has greatly expanded the understanding of mechanisms involved in xylitol synthesis by yeast, which is essential to develop sustainable xylitol production systems based on renewable raw material. However, the full potential of the technology for production at large scale, needs to be improved to reach industrial applications.

\subsection{Furans: furandicarboxylic acid and other hydroxymethylfurfural/ furfural-derivatives}

Furfural and hydroxymethylfurfural (HMF) are valuable building blocks, given their versatile composition: an aromatic furan ring and reactive functional groups (aldehyde group in furfural; aldehyde and alcohol groups in HMF). This makes them attractive building block platforms, as they can be transformed into higher value derivative compounds, having applications in several areas such as plastic, pharmaceutical, fragrance and textile industries (Fig. 3). Accordingly, the global market of furfural and HMF are expected to reach $\$ 700$ million and $\$ 61$ million by 2024, respectively (Markets and Markets, 2019; Market Study Report, 2019). Furfural and HMF are commonly present in lignocellulosic hydrolysates and are usually regarded as microbial inhibitors. They derive from the dehydration of pentoses and hexoses, respectively, and their accumulation depends on the biomass used, and on the type and severity of pretreatment and hydrolysis applied. As their value has been receiving growing attention, and while their microbial production has not yet been reported, several studies focus on optimizing pretreatment methods to increase furfural and HMF accumulation from lignocellulosic biomasses by using different catalysts and/or reaction media (e.g. ionic liquids, Lewis acids, Brönsted acids, solid acid catalysts, salts) as well as alternative heating methods (e.g. microwave) (Chen et al., 2020; Luo et al., 2019; Morais et al., 2020; Peleteiro et al., 2016; Steinbach et al., 2017; Sweygers et al., 2018; Zhang and Zhao, 2010).

At the same time, increased importance has been given to furfural and HMF as substrates for biotransformation into higher value furanderivatives. Some microorganisms can use furfural and/or HMF as sole carbon sources (Crigler et al., 2020; Igeño et al., 2018; Koopman et al., 2010), being promising bioprospecting tools for identification of enzymes for production of furan-derivatives in more suitable hosts. S. cerevisiae is incapable of using furfural or HMF as carbon source but can convert them into less toxic compounds. In fact, this yeast has long been known to perform a NAD(P)H-dependent reduction of furfural and HMF into their corresponding alcohols: furfuryl alcohol and 2,5-bishydroxymethylfuran (BHMF), respectively (Liu et al., 2008). Nevertheless, this capacity has been mainly studied from the point of view of fermentation media detoxification to improve second-generation bioethanol production instead of the possible production of these furan alcohols. In fact, only a few studies focus on the production of furfuryl alcohol using S. cerevisiae (Diaz De Villegas et al., 1992; Villa et al., 1992; Liu et al., 2005; Mandalika et al., 2014; Yan et al., 2019). Even without strain improvement, high yields of furfuryl alcohol were obtained from high levels of furfural: $96 \%$ yield from $30 \mathrm{~g} / \mathrm{L}$ of furfural in 
Table 3

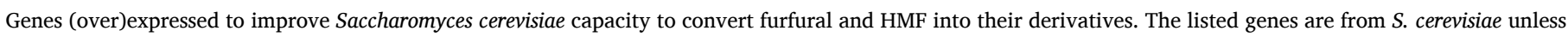

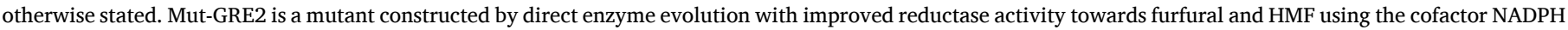

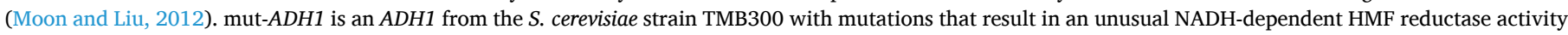
(Laadan et al., 2008).

\begin{tabular}{|c|c|c|}
\hline Substrate/Product & Genes & Reference \\
\hline \multicolumn{3}{|c|}{ (1) coding for NAD(P)H-dependent reductases/alcohol dehydrogenases } \\
\hline \multirow[t]{3}{*}{ Furfural/Furfuryl alcohol } & $A D H 1$ & Hasunuma et al., 2014; Ishii et al., 2013 \\
\hline & ORF YKL071W & Heer et al., 2009 \\
\hline & ORF YNL134C & Zhao et al., 2015 \\
\hline \multirow[t]{3}{*}{ HMF/BHMF } & mut-GRE2 & Moon and Liu, 2012 \\
\hline & SFA1 & Petersson et al., 2006 \\
\hline & ADH genes from Meyerozyma guilliermondii SC1103 & Xia et al., 2020 \\
\hline \multirow{5}{*}{$\begin{array}{l}\text { Furfural/Furfuryl alcohol } \\
\text { and } \\
\text { HMF/BHMF }\end{array}$} & mut- $A D H 1$ & Almeida et al., 2008a; Laadan et al., 2008; Ishii et al., 2013 \\
\hline & ADH6 & Petersson et al., 2006; Almeida et al., 2008a; Ishii et al., 2013 \\
\hline & $A D H 7$ & Heer et al., 2009 \\
\hline & ARI1 & Divate et al., 2017; Liu and Moon, 2009 \\
\hline & XYL1 from Scheffersomyces stipitis & Almeida et al., 2008b \\
\hline \multicolumn{3}{|c|}{ (2) involved in the regeneration of $\mathrm{NAD}(\mathrm{P}) \mathrm{H}$} \\
\hline \multirow[t]{2}{*}{$\mathrm{NADP}^{+} / \mathrm{NADPH}$} & $Z W F 1$ & Gorsich et al., 2006 \\
\hline & ALD6 & Park et al., 2011 \\
\hline $\mathrm{NAD}(\mathrm{P})^{+} / \mathrm{NAD}(\mathrm{P}) \mathrm{H}$ & XYL1/XYL2 from S. stipitis & Cunha et al., 2019b \\
\hline \multicolumn{3}{|c|}{ (3) overexpression of genes coding for NADPH-dependent aldehyde dehydrogenases } \\
\hline $\begin{array}{l}\text { Furfural/Furoic acid } \\
\text { and } \\
\text { HMF/HMFCA }\end{array}$ & $A L D 6$ & Park et al., 2011 \\
\hline
\end{tabular}

fed-batch (Villa et al., 1992) and 93\% from $25 \mathrm{~g} / \mathrm{L}$ in batch (Mandalika et al., 2014). This shows the potential of $S$. cerevisiae as a whole-cell biocatalyst for production of furan-derivatives. Regarding BHMF, its production by this yeast is even less explored (Liu et al., 2005). The first study where BHMF was confirmed as the reduction product of HMF by S. cerevisiae dates from 2004 (Liu et al., 2004). Despite that, a recent study focused on improving BHMF production from HMF used recombinant $S$. cerevisiae strains harbouring different alcohol dehydrogenases (ADHs) from Meyerozyma guilliermondii SC1103 and obtained $345 \mathrm{mM}$ of BHMF with a selectivity higher than $99 \%$ (Xia et al., 2020). These reductions of furfural and HMF by $S$. cerevisiae occur in anaerobic conditions, while aerobic conditions favour the oxidation of these compounds into furoic acid and 5-hydroxymethyl-2-furancarboxylic acid (HMFCA), respectively (Taherzadeh et al., 2000; Taherzadeh et al., 1999).

Several studies described genetic modifications to improve S. cerevisiae capacity to convert furfural and HMF into their derivatives (Fig. 3). These mainly rely on three different strategies: (1) (over) expression of genes coding for $\mathrm{NAD}(\mathrm{P}) \mathrm{H}$-dependent reductases/alcohol dehydrogenases directly involved in the reduction of these compounds, (2) (over)expression of genes involved in the regeneration of $\mathrm{NAD}(\mathrm{P}) \mathrm{H}$, to potentiate the activity of the reduction enzymes and (3) overexpression of genes coding for NADPH-dependent aldehyde dehydrogenases directly involved in the oxidation of furfural and HMF (Fig. 3, Table 3). While mainly analysed from a detoxification perspective, these strategies present valid tools to improve the production of furfural- and HMF-derivatives in $S$. cerevisiae through genetic engineering, which is currently an underexploited area.

Besides the ones mentioned, other high-value derivatives may be obtained from furfural and HMF. Among these, furandicarboxylic acid (FDCA), an HMF-derivative, has also been identified as one of the top products to be obtained from biomass and its worldwide market is expected to reach $\$ 850$ million by 2025 (Acumen Research and Consulting, 2019). Its main application is the polymerization with ethylene glycol for the production of PEF (polyethylene furanoate) to substitute the petroleum-derived PET (polyethylene terephthalate) plastic. In fact, a consortium of eleven companies named "PEFerence", was funded by the Europen Union's Horizon 2020 to establish an innovative biobased production of FDCA and PEF (https://peference.eu/). FDCA is obtained by oxidation of HMF, and some microorganisms such as Acinetobacter oleivorans, Aspergillus flavus or Burkholderia cepacian (Godan et al., 2019;
Rajesh et al., 2019; Yang and Huang, 2016) have the innate capacity to produce it. Nevertheless, most industries depend on chemical processes for its production, with Corbion being a pioneer in using microbial biocatalyst to produce FDCA from HMF. In a recent patented study, a laboratory $S$. cerevisiae was engineered to produce FDCA (de Bont et al., 2018). In a first attempt HMF-oxidase ( $\mathrm{hmfH}$ ) and HMF/FFCA dehydrogenase (Adh) from Cupriavidus basilensis HMF14 were expressed but resulted in the production of only $0.033 \mathrm{~g} / \mathrm{L}$ of FDCA from $\sim 0.5 \mathrm{~g} / \mathrm{L}$ of HMF. Subsequently, the expression of alcohol dehydrogenase ( $h m f L 1$ ) and aldehyde dehydrogenase ( $h m f N 1)$ from Penicillium brasilianum resulted in the production of $0.47 \mathrm{~g} / \mathrm{L}$ of FDCA from approximately the same HMF concentration. In similar conditions, the control wild-type $S$. cerevisiae strain produced no FDCA but accumulated $0.41 \mathrm{~g} / \mathrm{L}$ of HMFCA. Despite the low values obtained, $S$. cerevisiae presents as a promising host for FDCA production, due to its high tolerance towards HMF and innate capacity to produce the intermediate HMFCA (Fig. 3). The development of more efficient FDCA-producing $S$. cerevisiae strains still requires further research in terms of genetic engineering approaches (e.g. following approaches already used in other microorganisms or expressing enzymes with reported activity for conversion of HMF into FDCA), but also in terms of optimization of process conditions (such as oxygen availability, temperature and $\mathrm{pH}$ ).

\subsection{Biohydrocarbons: isoprene}

Hydrocarbons are valuable products due to their high energy density, both on a mass and volume basis (Peralta-Yahya and Keasling, 2010). Isoprene $\left(\mathrm{C}_{5} \mathrm{H}_{8}\right)$, also identified as 2-methyl-1,3-butadiene, is a volatile hydrophobic terpenoid hydrocarbon (Hong et al., 2012) with several industrial applications, from the production of synthetic rubber for tires and coatings to potential fuel additive for gasoline or diesel (Bentley et al., 2014). The worldwide isoprene market is approximately $\$ 3$ thousand million, with a projected CAGR of over 7\%, attaining a predictable value of near $\$ 4$ thousand million by 2025 (Market Research Future, 2020). Nowadays, its production relies almost entirely on petrochemical sources, being commonly obtained by dehydrogenation of C5 isoalkanes and isoalkenes or via direct isolation from C5 cracking fractions (Weissermel and Arpe, 1992). Besides its dependence on the C5 supply, which is gradually diminishing due to the employment of new technologies in petrochemical chemistry, its chemical synthesis is 
Table 4

S. cerevisiae metabolic engineering strategies for the production of organic acids: (lactic, succinic and 3-hydroxypropionic) and biohydrocarbons (isoprene)

\begin{tabular}{|c|c|c|c|}
\hline Reference & Strategy & Main results & Substrate \\
\hline Hong et al., 2012 & $\begin{array}{l}\text { Multiple copies of codon optimized isoprene synthase gene (IspS) from } \\
\text { P. montana }\end{array}$ & $0.5 \mathrm{mg} / \mathrm{L}$ of isoprene & Galactose \\
\hline Lv et al., 2014 & $\begin{array}{l}\text { Engineering of the native acetyl-CoA and mevalonic acid pathways } \\
\text { (BY } 4741 \text {, p2 copies of codon optimized ispS from } P \text {. alba, } p t H M G 1, I D I 1 \text {, } \\
\text { ACS2 ERG10 from } S \text {. cerevisiae, down-regulation of } E R G 20 \text { by promoter } \\
\text { replacement) }\end{array}$ & $\begin{array}{l}37 \mathrm{mg} / \mathrm{L} \text { of isoprene (about } 782 \text {-fold increase } \\
\text { compared to the parental strain); yield } 0.025 \mathrm{~g} / \mathrm{g}\end{array}$ & $\begin{array}{l}\text { Sucrose and } \\
\text { glycerol }\end{array}$ \\
\hline Lv et al., 2016 & $\begin{array}{l}\text { Dual metabolic engineering of cytoplasmic and mitochondrial acetyl-CoA } \\
\text { utilization; hibridization of strains }\end{array}$ & $2527 \mathrm{mg} / \mathrm{L}$ of isoprene & Sucrose \\
\hline Wang et al., 2017 & $\begin{array}{l}\text { Development of PGAL1-controlled ISPS by overexpression of GAL4; } \triangle \text { gal1/ } \\
7 / 10 \text { promoters; disruption of GAL80 and insertion of an ISPSM } 4 \text { mutant } \\
\text { from direct evolution }\end{array}$ & $\begin{array}{l}640 \mathrm{mg} / \mathrm{L} \text { and } 3.7 \mathrm{~g} / \mathrm{L} \text { of isoprene in aerobic batch } \\
\text { (from sucrose) and fed-batch (from glucose) } \\
\text { fermentations, respectively }\end{array}$ & $\begin{array}{l}\text { Sucrose and } \\
\text { glucose }\end{array}$ \\
\hline Yao et al., 2018 & $\begin{array}{l}\text { Hybridization of BY4741-M-08-HIS and YXM54, followed by } \\
\text { transformation with high-copy plasmid pESC-URA-ISPSLN-MISPSLN }\end{array}$ & $\begin{array}{l}1.044 \mathrm{~g} / \mathrm{L} \text { of isoprene in batch conditions; } 11.9 \mathrm{~g} / \mathrm{L} \\
\text { isoprene in fed-batch }\end{array}$ & Glucose \\
\hline
\end{tabular}

energy-consuming and environmentally unfriendly, and its yields might be insufficient for future demand (Ye et al., 2016). Unlike other biobased chemicals, and due to its low boiling point, of $34^{\circ} \mathrm{C}$, and low solubility in water, isoprene can be continuously recovered as a gas in fermentation processes, which has some potential benefits such as reduction of product feedback inhibition and efficient recovery and purification (Ye et al., 2016).

Isoprene is produced by both eukaryotes and prokaryotes, including humans, plants, yeast, and bacteria (Kuzuyama, 2002), being the most produced biogenic volatile organic compound in the planet with atmospheric emissions of ca. $500 \mathrm{Tg}(\mathrm{C})$ per year (Murrell et al., 2020). Plants are the major annual isoprene producer among all organisms, reaching around 600 million tonnes per year (Guenther et al., 2006). Even though plants have a high isoprene yield, its economical exploitation in a commercial perspective is not viable, due to the difficulty of collecting this volatile compound from the vast canopy of leafy plants (Ye et al., 2016). Despite the small global contribution, microbial production of isoprene is also ubiquitous in nature. The common soil bacterium $B$. subtilis is found to be the best natural bacterial producer of isoprene (Kuzma et al., 1995), but $E$. coli has been the most broadly explored microorganism as recombinant cell factory, yielding up to $24 \mathrm{~g} / \mathrm{L}$ of isoprene production (Yao et al., 2018). Over the last decade, some studies have focused on the production of isoprene using $S$. cerevisiae as host in multiple substrates (Table 4). Hong et al. (2012) engineered a strain where multiple copies of codon-optimized isoprene synthase (ISPS) gene from Pueraria montana were expressed, which led to a production of $0.5 \mathrm{mg} / \mathrm{L}$ of isoprene from galactose. A different study stemmed on the engineering of the native cytoplasmatic acetyl-CoA and mevalonic acid pathways to enhance the metabolic flux towards isoprene synthesis, achieving a production of $37 \mathrm{mg} / \mathrm{L}$ of isoprene using sucrose and glycerol as carbon sources (Lv et al., 2014). Then, dual metabolic engineering of both cytoplasmic and mitochondrial acetylCoA utilization boosted isoprene synthesis, yielding $2.527 \mathrm{~g} / \mathrm{L}$ of isoprene from sucrose (Lv et al., 2016). More recently, an approach on directed evolution of ISPS, coupled with Gal4p-mediated expression enhancement, led to a production up to $3.7 \mathrm{~g} / \mathrm{L}$ in fed-batch conditions from glucose (Wang et al., 2017). Yao et al. (2018) have reported a strategy for improved isoprene biosynthesis by simultaneous strengthening of precursor supply and conversion via a combination of pathway compartmentation and protein engineering. Initially, a superior isoprene synthase mutant ISPSLN was created by saturation mutagenesis, which resulted in a near 4-fold improvement in isoprene production. Subsequent introduction of ISPSLN into strains with strengthened precursor supply in either cytoplasm or mitochondria led to a metabolic imbalance between the upstream and downstream flux, solved by expressing additional copies of diphosphomevalonate decarboxylase gene (MVD1) and isopentenyl-diphosphate delta-isomerase gene (IDI1) into the cytoplasmic and mitochondrial engineered strains. Lastly, by hybridization of these two haploid strains, the resultant diploid strain yielded $11.9 \mathrm{~g} / \mathrm{L}$ in fed-batch with glucose as carbon source, the highest concentration reported to date in eukaryotic cells. Nonetheless, achieving maximal yield of isoprene is still an upcoming challenge to tackle, either through direct evolution or finding novel enzymes and/or metabolic engineering strategies to maximize carbon flux into this target compound.

\subsection{Glycerol and derivatives}

Glycerol $\left(\mathrm{C}_{3} \mathrm{H}_{8} \mathrm{O}_{3}\right)$ is a polyol with a wide range of commercial applications. It has been widely used in the manufacture of skin care products, medicines and toothpastes to increase humidity, viscosity and smoothness, and included in food products as solvent, preservative and softening agent (Tan et al., 2013). In addition, glycerol shows great potential on becoming a primary building block for biorefineries (Bozell and Petersen, 2010). It can be produced by chemical synthesis from propylene, by microbial fermentation or can be recovered as by-product resulting from the transesterification of fats and oils in biodiesel manufacturing (Wang et al., 2001). Currently, the demand for renewable fuels is expanding the biodiesel industry, leading to crude glycerol overproduction. This biodiesel-derived crude glycerol contains processrelated impurities (salts, proteins, methanol, soap, triglycerides, fatty acids and metals) and its utilization requires purification and refining processes that are not economically viable (Kumar et al., 2019).

Considering the growing demand for non-petroleum derived products and the safety concerns regarding chemical manufacturing procedures, research has been carried out to develop efficient biotechnological processes for glycerol production, focusing mainly on yeasts. S. cerevisiae naturally produces glycerol as a by-product during alcoholic fermentation. It is formed from the glycolytic intermediate dihydroxyacetone phosphate (DHAP) through the action of two isoforms of glycerol-3-phosphate dehydrogenase (GPDH) and glycerol-3phosphatase (GPP), encoded by GPD1/GPD2 and GPP1/GPP2 homologous genes, respectively (Fig. 4) (Gancedo et al., 1968; Wang et al., 2001). Several genetic engineering strategies have been explored to improve glycerol synthesis in $S$. cerevisiae. Some of the strategies included the expression of genes directly involved in glycerol formation. For example the overexpression of the GPD1 resulted in a 4-fold enhanced glycerol production (Michnick et al., 1997; Remize et al., 2001). Other approaches aimed at redirecting carbon flux from ethanol towards glycerol production by reducing the activity of enzymes involved in alcoholic fermentation (Cordier et al., 2007; Drewke et al., 1990; Nevoigt and Stahl, 1996). Alternatively, the deletion of TPI1 gene, coding for the triose phosphatase isomerase responsible for the conversion of DHAP to glyceraldehyde-3-phosphate (Fig. 4), resulted in an improved glycerol yield and productivity (Compagno et al., 1996). However, the inactivation of this glycolytic enzyme led to an 


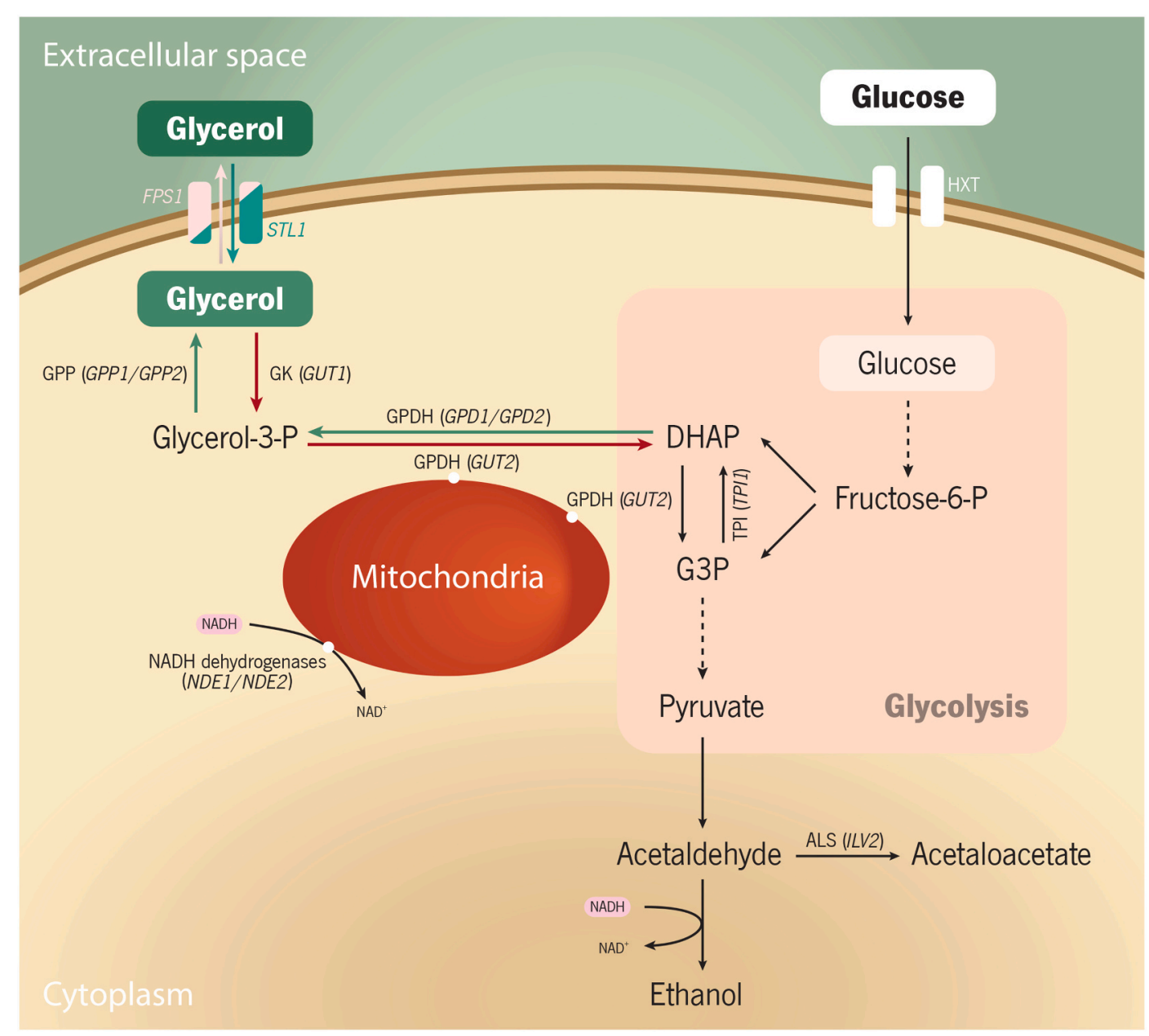

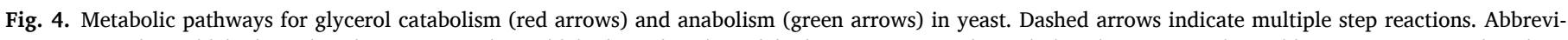

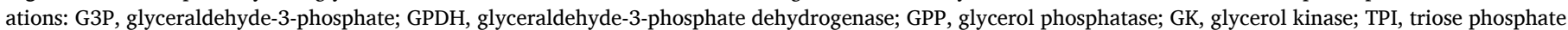

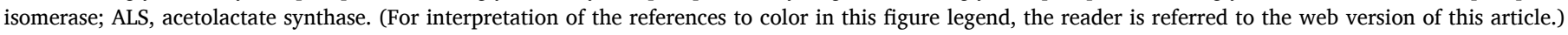

accumulation of DHAP, which affected negatively the growth on glucose as sole carbon source. This glucose growth defect was partially circumvented by the deletion of GUT2 gene and NDE1 and NDE2 isogenes. GUT2 encodes for a mitochondrial respiratory-chain-linked GPDH that catalyses the reversible conversion of glycerol-3-phosphate (G3P) to DHAP while NDE1/NDE2 isogenes encode for NADH dehydrogenases enzymes responsible for the mitochondrial reoxidation of cytosolic NADH (Fig. 4). Considering the requirement of NADH for the conversion of DHAP to glycerol, the inactivation of these NADH dehydrogenases increased the availability of cytosolic NADH, reducing the accumulation of DHAP. Additionally, evolutionary engineering of this recombinant S. cerevisiae strain (tpi1 $\Delta$ nde1 $\Delta$ nde2 $\Delta$ gut $2 \Delta$ quadruple mutant) improved the specific growth rates in high-glucose and yielded $200 \mathrm{~g} / \mathrm{L}$ of glycerol (Overkamp et al., 2002).

More recently, the expression of the truncated version of ILV2 gene resulted in a 4-fold increase in glycerol production, comparing with the wild-type strain. ILV2 codes for a mitochondrial acetolactate synthase that catalyses the first step in isoleucine and valine biosynthesis, converting two pyruvate molecules into one acetolactate molecule. The truncated ILV2 gene, lacking a mitochondria targeting sequence, encodes a cytosolic form of acetolactate synthase (Fig. 4). The retention of the acetolactate synthase on the cytosol resulted on the conversion of pyruvate to acetolactate, decreasing the available pyruvate for ethanol formation and limiting the acetaldehyde synthesis, thereby increasing NADH availability for glycerol production (Murashchenko et al., 2016). Semkiv et al. (2017) described a more efficient process for the production of glycerol as the primary product under anaerobic conditions. For this, the overexpression of the ILV2 truncated gene and FPS1 coding for aquaglyceporin (involved in glycerol efflux), combined with decreased expression of TPI1 and overexpression of a fused gene coding for GPDH resulted in the production of $16 \mathrm{~g} / \mathrm{L}$ of glycerol (Semkiv et al., 2017).

In addition to being sold for a variety of uses, glycerol can be converted into other valuable chemicals. Moreover, the need to implement valorisation routes for crude glycerol has drawn attention for the use of this waste stream as substrate for the production of high-value chemicals by microorganisms. The use of biotechnology, especially fermentation technologies, is a promising alternative to convert crude glycerol into higher value products since it requires less energy input (occurs at milder conditions), which may offset the disposal costs of crude glycerol (Kaur et al., 2012). In addition, glycerol presents an higher degree of reduction per carbon compared to the commonly used sugar substrates (glucose and xylose), which results in higher maximum theoretical yields of target reduced compounds (Clomburg and Gonzalez, 2013).

Some biotechnological processes using glycerol as feedstock have already been developed in Clostridium species (Gonzalez-Pajuelo et al., 2005). However, the utilization of glycerol by $S$. cerevisiae still poses a challenge, since wild-type strains cannot efficiently grow using glycerol as carbon source without nutrient supplementation (Swinnen et al., 2016). The native L-glycerol-3-phosphate pathway has been reported as the main route for glycerol catabolism in S. cerevisiae. This pathway, with glycerol-3-phosphate as intermediate, involves the action of two 
Table 5

Development stages of high value compounds production in Saccharomyces cerevisiae.

\begin{tabular}{|c|c|c|c|c|}
\hline Compounds & $\begin{array}{l}\text { Production in } \\
\text { S. cerevisiae }\end{array}$ & $\begin{array}{l}\text { Genetic engineering to increase/allow } \\
\text { production }\end{array}$ & $\begin{array}{l}\text { Production using industrial/wild } \\
\text { S. cerevisiae }\end{array}$ & $\begin{array}{l}\text { Production from renewable } \\
\text { carbons }\end{array}$ \\
\hline Lactic acid & YES & YES & YES & YES \\
\hline Succinic acid & YES & YES & NO & NO \\
\hline 3-HP & YES & NO & YES & NO \\
\hline Levulinic acid & NO & NO & NO & NO \\
\hline Sorbitol & YES & NO & NO & NO \\
\hline Xylitol & YES & YES & YES & YES \\
\hline FDCA & YES & YES & NO & NO \\
\hline $\begin{array}{l}\text { Other HMF- } \\
\text { derivatives }\end{array}$ & YES & YES & YES & NO \\
\hline Furfural-derivatives & YES & YES & YES & NO \\
\hline Isoprene & YES & YES & NO & NO \\
\hline Glycerol/derivatives & YES & YES & NO & NO \\
\hline
\end{tabular}

enzymes: a glycerol kinase (GUT1) and a GPDH (GUT2) for the conversion of glycerol into DHAP, which is further directed to the glycolysis and gluconeogenesis (Fig. 4) (Klein et al., 2017). DHAP can also be used as a metabolic precursor to produce 1,2-propanediol (propylene glycol), an important chemical that is applied as humectant and food preservative. Jung et al. (2011) successfully engineered $S$. cerevisiae for 1,2-propanediol production, using glycerol as carbon source. The overexpression of GUP1 (involved in glycerol consumption and metabolism) and glycerol-3-phosphate pathway genes (GUT1 and GUT2) together with the expression of the heterologous glycerol dehydrogenase gene $(g d h)$ from Pichia angusta improved the glycerol uptake rate. In addition, the introduction of $E$. coli methylglyoxal pathway genes ( $m g s A$ and gldA, coding for methylglyoxal synthase and glycerol dehydrogenase) responsible for the conversion of DHAP to 1,2-propanediol, resulted in $2.19 \mathrm{~g} / \mathrm{L}$ of 1,2-propanediol (Jung et al., 2011). For the exploitation of the abovementioned glycerol reducing power, the electrons derived from glycerol oxidation must be saved in the form of cytosolic NAD(P)H. However, the electrons resulting from glycerol oxidation through the L-glycerol-3-phosphate pathway are transferred via $\mathrm{FADH}_{2}$ to the mitochondrial respiratory chain (Klein et al., 2016). Therefore, the L-glycerol-3-phosphate native pathway was replaced by a synthetic $\mathrm{NAD}^{+}$-dependent DHA pathway. This strategy involved the GUT1 gene deletion and the expression of $g d h$ gene from the yeast Ogataea parapolymorpha, coding for $\mathrm{NAD}^{+}$-dependent glycerol dehydrogenase for oxidation of glycerol to dihydroxyacetone (DHA), alongside the overexpression of the native DAK1 gene, coding for glycerol kinase, involved in the subsequent phosphorylation of DHA (Klein et al., 2016). This improved strain was used to introduce the heterologous methylglyoxal pathway and to increase precursor (DHAP) supply by reducing triosephosphate isomerase (TPI) activity, resulting in the highest titre of 1,2-propanediol obtained in yeast ( $>4 \mathrm{~g} / \mathrm{L}$ ) (Islam et al., 2017).

Progress has been made in metabolic engineering of $S$. cerevisiae for glycerol biosynthesis and also to generate strains with superior capacity to use glycerol as carbon source for the production of glycerol derivatives. Considering that high production cost is the major drawback for the implementation of industrial processes for glycerol biosynthesis, the achieved biotechnological advancements need to be coupled with metabolic engineering approaches to improve yeast tolerance to lignocellulose-based process conditions, opening new opportunities for utilizing biomass-derived carbohydrate sources. A strong improvement is also expected regarding the production of useful chemicals from glycerol by $S$. cerevisiae. Although significant research advancements continue to be made, there is still a narrow range of derivative compounds produced from glycerol. Given the potential of glycerol as a substrate, novel bioconversions routes may help to expand the plethora of its derivatives.

\section{Concluding remarks}

The implementation of a sustainable biobased economy relies on the substitution of single product biorefineries for integrated versions producing biofuels combined with biobased products. An encouraging approach would be combining second-generation bioethanol manufacture with the production of key value-added chemicals: organic acids (lactic, succinic, levulinic and 3-hydroxypropionic acids), sugar alcohols (xylitol and sorbitol), furans and derivatives (hydroxymethylfurfural, furfural and furandicarboxylic acid), biohydrocarbons (isoprene), and glycerol and its derivatives (Bozell and Petersen, 2010). The extensive know-how of $S$. cerevisiae metabolism in inexpensive renewable feedstocks, such as lignocellulosic biomass, poses as an advantage to make this yeast a suitable production platform and substitute the chemical routes to produce target top value compounds as well as their higher value derivatives. Significant progress on metabolic pathway design and optimization, transport engineering and carbon partition strategies has been fuelling the development of $S$. cerevisiae for the production of these value-added chemicals. At this moment, there are reports of $S$. cerevisiae strain optimization to produce 8 out of the 11 top value chemicals here revised: FDCA, isoprene, 1,2-propanediol (glycerol derivatives), lactic, succinic and 3-hydroxypropionic acids, sorbitol and xylitol. Table 5 provides a comparison between research advances on $S$. cerevisiae for the production of the 11 products with identification of whether the production of the target compound has been reported in S. cerevisiae and in particular, on industrial strains, if there are reports on genetic engineering approaches for increased production and finally if the production from renewable carbons has been reported. Clearly, the development stage is quite differentiated among target products. Xylitol, followed by lactic acid, stand out as the most advanced with promising demonstrated lab-scale production processes from lignocellulosic biomasses. Furthermore, most of the top value compounds show potential as building blocks platforms, and higher value products may be obtained from them using $S$. cerevisiae, e.g. furfuryl alcohol, HMFCA, 1,2-propanediol. The efforts to construct strains for consolidated bioprocessing, containing lignocellulose-degrading enzymes for the direct conversion of biomass into bioethanol, allow their application for the production of value-added chemicals, such as xylitol, decreasing the overall cost of the process and solving problems like catabolic repression. Implementation of integrated biorefineries will ultimately rely on the development of metabolic routes for the production of value-added chemicals from renewable carbohydrates with high titres, yield and productivity in industrial strains of $S$. cerevisiae. Furthermore, the upsurge of disruptive tools like CRISPR/Cas9 and other alternative CRISPR systems is already making noticeable progress to the expansion of genome editing toolbox available for $S$. cerevisiae (Verwaal et al., 2018). This will progressively allow faster strain engineering and multiple simultaneous genome edits (independent of marker cassette integration), as well as optimal transcriptional regulation, resulting in more stable strains - a requirement for their use in industrial processes. In this sense, $S$. cerevisiae offers 
unique advantages to develop microbial cell factories for these integrated biorefineries, coupling environmentally friendly and economically feasible production of ethanol and value-added compounds.

\section{Declaration of Competing Interest}

None

\section{Acknowledgements}

This work was supported by the Portuguese Foundation for Science and Technology (FCT) under the scope of the strategic funding of UIDB/ 04469/2020, the PhD grants (SFRH/BD/132717/2017 to SLB, SFRH/ $\mathrm{BD} / 130739 / 2017$ to CEC and SFRH/BD/146367/2019 to POS), the MIT-Portugal Program (Ph.D. Grant PD/BD/128247/2016 to JTC), BioTecNorte operation (NORTE-01-0145-FEDER-000004) and Biomass and Bioenergy Research Infrastructure (BBRI)- LISBOA-01-0145-FEDER022059 funded by the European Regional Development Fund (ERDF) under the scope of Norte2020 - Programa Operacional Regional do Norte.

\section{References}

Acumen Research and Consulting, 2019. 2,5-Furandicarboxylic Acid (FDCA) Market Size Worth Around \$850 Million By 2025: Acumen Research and Consulting. Available at: https://www.acumenresearchandconsulting.com/press-releases/2-5-furand icarboxylic-acid-fdca-market (Accessed: 31 July 2020).

Ahmad, A., Banat, F., Taher, H., 2020. A review on the lactic acid fermentation from lowcost renewable materials: Recent developments and challenges. Environ. Technol. Innov. 20, 101138. https://doi.org/10.1016/j.eti.2020.101138.

Almeida, J.R.M., Röder, A., Modig, T., Laadan, B., Lidén, G., Gorwa-Grauslund, M.-F., 2008a. NADH- vs NADPH-coupled reduction of 5-hydroxymethyl furfural (HMF) and its implications on product distribution in Saccharomyces cerevisiae. Appl. Microbiol. Biotechnol. 78, 939-945. https://doi.org/10.1007/s00253-008-1364-y.

Almeida, J.R.M., Modig, T., Röder, A., Lidén, G., Gorwa-Grauslund, M.-F., 2008b. Pichia stipitis xylose reductase helps detoxifying lignocellulosic hydrolysate by reducing 5hydroxymethyl-furfural (HMF). Biotechnol. Biofuels 1, 12. https://doi.org/10.1186/ 1754-6834-1-12.

Andrade, R.P., Casal, M., 2001. Expression of the Lactate Permease Gene JEN1 from the Yeast Saccharomyces cerevisiae. Fungal Genet. Biol. 32 (2), 105-111. https://doi.org/ 10.1006/fgbi.2001.1254.

Bae, S.-M., Park, Y.-C., Lee, T.-H., Kweon, D.-H., Choi, J.-H., Kim, S.-K., Ryu, Y.-W., Seo, J.-H., 2004. Production of xylitol by recombinant Saccharomyces cerevisiae containing xylose reductase gene in repeated fed-batch and cell-recycle fermentations. Enzym. Microb. Technol. 35, 545-549.

Baek, S.-H., Kwon, E.Y., Kim, Y.H., Hahn, J.-S., 2016. Metabolic engineering and adaptive evolution for efficient production of D-lactic acid in Saccharomyces cerevisiae. Appl. Microbiol. Biotechnol. 100 (6), 2737-2748. https://doi.org/ 10.1007/s00253-015-7174-0.

Baek, S.-H., Kwon, E.Y., Bae, S.-J., Cho, B.-R., Kim, S.-Y., Hahn, J.-S., 2017. Improvement of D-Lactic Acid Production in Saccharomyces cerevisiae Under Acidic Conditions by Evolutionary and Rational Metabolic Engineering. Biotechnol. J. 12 (10), 1700015. https://doi.org/10.1002/biot.201700015.

Baptista, S.L., Cunha, J.T., Romaní, A., Domingues, L., 2018. Xylitol production from lignocellulosic whole slurry corn cob by engineered industrial Saccharomyces cerevisiae PE-2. Bioresour. Technol. 267, 481-491.

Baptista, S.L., Carvalho, L.C., Romaní, A., Domingues, L., 2020. Development of a sustainable bioprocess based on green technologies for xylitol production from corn cob. Ind. Crop. Prod. 156, 112867. https://doi.org/10.1016/j.indcrop.2020.112867.

Barbosa, M.F.S., de Medeiros, M.B., de Mancilha, I.M., Schneider, H., Lee, H., 1988. Screening of yeasts for production of xylitol from d-xylose and some factors which affect xylitol yield in Candida guilliermondii. J. Ind. Microbiol. 3, 241-251. https:// doi.org/10.1007/BF01569582.

Beale, S.I., 1970. The Biosynthesis of $\delta$-Aminolevulinic Acid in Chlorella. Plant Physiol. 45 (4), 504-506. https://doi.org/10.1104/pp.45.4.504.

Becker, J., Lange, A., Fabarius, J., Wittmann, C., 2015. Top value platform chemicals: Bio-based production of organic acids. Curr. Opin. Biotechnol. 36, 168-175. https:// doi.org/10.1016/j.copbio.2015.08.022.

Bender, T.A., Dabrowski, J.A., Gagné, M.R., 2018. Homogeneous catalysis for the production of low-volume, high-value chemicals from biomass. Nat. Rev. Chem. 2 , 35-46. https://doi.org/10.1038/s41570-018-0005-y.

Benninga, H., 1990. A history of lactic acid making: a chapter in the history of biotechnology. Kluwer Academic Publishers, Dordrecht, The Netherlands, p. 478.

Bentley, F.K., Zurbriggen, A., Melis, A., 2014. Heterologous Expression of the Mevalonic Acid Pathway in Cyanobacteria Enhances Endogenous Carbon Partitioning to Isoprene. Mol. Plant 7 (1), 71-86. https://doi.org/10.1093/mp/sst134.

Borodina, I., Nielsen, J., 2014. Advances in metabolic engineering of yeast Saccharomyces cerevisiae for production of chemicals. Biotechnol. J. 9, 609-620. https://doi.org/ 10.1002/biot.201300445.
Borodina, I., Kildegaard, K.R., Jensen, N.B., Blicher, T.H., Maury, J., Sherstyk, S., Schneider, K., Lamosa, P., Herrgård, M.J., Rosenstand, I., Öberg, F., Forster, J., Nielsen, J., 2015. Establishing a synthetic pathway for high-level production of 3 hydroxypropionic acid in Saccharomyces cerevisiae via $\beta$-alanine. Metab. Eng. 27, 57-64. https://doi.org/10.1016/j.ymben.2014.10.003.

Bozell, Joseph J., Petersen, G.R., 2010. Technology development for the production of biobased products from biorefinery carbohydrates - the US Department of Energy's "Top 10" revisited. Green Chem. 12, 539-554. https://doi.org/10.1039/B922014C.

Cha, J.S., Um, B.H., 2020. Levulinic acid production through two-step acidic and thermal treatment of food waste using dilute hydrochloric acid. Korean J. Chem. Eng. 37 (7), 1149-1156. https://doi.org/10.1007/s11814-020-0521-6.

Chen, Y., Nielsen, J., 2016. Biobased organic acids production by metabolically engineered microorganisms. Curr. Opin. Biotechnol. 37, 165-172. https://doi.org/ 10.1016/j.copbio.2015.11.004.

Chen, Y., Bao, J., Kim, I.-K., Siewers, V., Nielsen, J., 2014. Coupled incremental precursor and co-factor supply improves 3-hydroxypropionic acid production in Saccharomyces cerevisiae. Metab. Eng. 22, 104-109. https://doi.org/10.1016/j.ymben.2014.01.005.

Chen, X., Yang, X., Shen, Y., Hou, J., Bao, X., 2017a. Increasing Malonyl-CoA Derived Product through Controlling the Transcription Regulators of Phospholipid Synthesis in Saccharomyces cerevisiae. ACS Synth. Biol. 6 (5), 905-912. https://doi.org/ 10.1021/acssynbio.6b00346.

Chen, Z., Huang, J., Wu, Y., Wu, W., Zhang, Y., Liu, D., 2017b. Metabolic engineering of Corynebacterium glutamicum for the production of 3-hydroxypropionic acid from glucose and xylose. Metab. Eng. 39, 151-158. https://doi.org/10.1016/j. ymben.2016.11.009.

Chen, W.-C., Lin, Y.-C., Chu, I.M., Wang, L.-F., Tsai, S.-L., Wei, Y.-H., 2020. Feasibility of enhancing production of 5-hydroxymethylfurfural using deep eutectic solvents as reaction media in a high-pressure reactor. Biochem. Eng. J. 154, 107440.

Cherubini, F., 2010. The biorefinery concept: Using biomass instead of oil for producing energy and chemicals. Energy Convers. Manag. 51, 1412-1421. https://doi.org/ 10.1016/j.enconman.2010.01.015.

Chu, H.S., Kim, Y.S., Lee, C.M., Lee, J.H., Jung, W.S., Ahn, J.-H., Song, S.H., Choi, I.S., Cho, K.M., 2015. Metabolic engineering of 3-hydroxypropionic acid biosynthesis in Escherichia coli. Biotechnol. Bioeng. 112 (2), 356-364. https://doi.org/10.1002/ bit.25444.

Chung, Y.-S., Kim, M.-D., Lee, W.-J., Ryu, Y.-W., Kim, J.-H., Seo, J.-H., 2002. Stable expression of xylose reductase gene enhances xylitol production in recombinant Saccharomyces cerevisiae. Enzym. Microb. Technol. 30, 809-816. https://doi.org/ 10.1016/S0141-0229(02)00062-5.

Clomburg, J.M., Gonzalez, R., 2013. Anaerobic fermentation of glycerol: a platform for renewable fuels and chemicals. Trends Biotechnol. 31, 20-28. https://doi.org/ 10.1016/j.tibtech.2012.10.006.

Cok, B., Tsiropoulos, I., Roes, A.L., Patel, M.K., 2014. Succinic acid production derived from carbohydrates: An energy and greenhouse gas assessment of a platform chemical toward a bio-based economy. Biofuels Bioprod. Biorefin. 8 (1), 16-29. https://doi.org/10.1002/bbb.1427.

Colombié, S., Dequin, S., Sablayrolles, J., 2003. Control of lactate production by Saccharomyces cerevisiae expressing a bacterial $L D H$ gene. Enzym. Microb. Technol. 33 (1), 38-46. https://doi.org/10.1016/S0141-0229(03)00082-6.

Cordier, H., Mendes, F., Vasconcelos, I., François, J.M., 2007. A metabolic and genomic study of engineered Saccharomyces cerevisiae strains for high glycerol production. Metab. Eng. 9, 364-378. https://doi.org/10.1016/j.ymben.2007.03.002.

Costa, C.E., Romaní, A., Cunha, J.T., Johansson, B., Domingues, L., 2017. Integrated approach for selecting efficient Saccharomyces cerevisiae for industrial lignocellulosic fermentations: Importance of yeast chassis linked to process conditions. Bioresour. Technol. 227, 24-34. https://doi.org/10.1016/j.biortech.2016.12.016.

Crigler, J., Eiteman, M.A., Altman, E., 2020. Characterization of the Furfural and 5Hydroxymethylfurfural (HMF) Metabolic Pathway in the Novel Isolate Pseudomonas putida ALS1267. Appl. Biochem. Biotechnol. 190, 918-930. https://doi.org/ 10.1007/s12010-019-03130-x.

Cunha, J.T., Aguiar, T.Q., Romaní, A., Oliveira, C., Domingues, L., 2015. Contribution of PRS3, RPB4 and ZWF1 to the resistance of industrial Saccharomyces cerevisiae CCUG53310 and PE-2 strains to lignocellulosic hydrolysate-derived inhibitors. Bioresour. Technol. 191, 7-16. https://doi.org/10.1016/j.biortech.2015.05.006.

Cunha, J.T., Costa, C.E., Ferraz, L., Romaní, A., Johansson, B., Sá-Correia, I., Domingues, L., 2018a. HAA1 and PRS3 overexpression boosts yeast tolerance towards acetic acid improving xylose or glucose consumption: unravelling the underlying mechanisms. Appl. Microbiol. Biotechnol. 102 (10), 4589-4600. https:// doi.org/10.1007/s00253-018-8955-z.

Cunha, M., Romaní, A., Carvalho, M., Domingues, L., 2018b. Boosting bioethanol production from Eucalyptus wood by whey incorporation. Bioresour. Technol. 250, 256-264. https://doi.org/10.1016/j.biortech.2017.11.023.

Cunha, J.T., Romaní, A., Costa, C.E., Sá-Correia, I., Domingues, L., 2019a. Molecular and physiological basis of Saccharomyces cerevisiae tolerance to adverse lignocellulosebased process conditions. Appl. Microbiol. Biotechnol. 103, 159-175. https://doi. org/10.1007/s00253-018-9478-3.

Cunha, J.T., Soares, P.O., Romaní, A., Thevelein, J.M., Domingues, L., 2019b. Xylose fermentation efficiency of industrial Saccharomyces cerevisiae yeast with separate or combined xylose reductase/xylitol dehydrogenase and xylose isomerase pathways. Biotechnol. Biofuels 12, 1-14. https://doi.org/10.1186/s13068-019-1360-8.

Cunha, J.T., Soares, P.O., Baptista, S.L., Costa, C.E., Domingues, L., 2020. Engineered Saccharomyces cerevisiae for lignocellulosic valorisation: a review and perspectives on bioethanol production. Bioengineered. https://doi.org/10.1080/ 21655979.2020.1801178.

Dasgupta, D., Bandhu, S., Adhikari, D.K., Ghosh, D., 2017. Challenges and prospects of xylitol production with whole cell bio-catalysis: A review. Microbiol. Res. 197, 9-21. 
David, F., Nielsen, J., Siewers, V., 2016. Flux Control at the Malonyl-CoA Node through Hierarchical Dynamic Pathway Regulation in Saccharomyces cerevisiae. ACS Synth. Biol. 5 (3), 224-233. https://doi.org/10.1021/acssynbio.5b00161.

de Bont, J.A.M., Ruijssenaars, H.J., Werij, J., 2018. Fungal production of FDCA. US. patent 20180265896.

De Jong, E., Stichnothe, H., Bell, G., Jørgensen, H., de Bari, I., van Haveren, J., Lindorfer, J., 2020. Bio-Based Chemicals A 2020 Update. Technical report IEA Bioenergy: Task 42, 2020.

del Río, P.G., Domínguez, E., Domínguez, V.D., Romaní, A., Domingues, L., Garrote, G., 2019. Third generation bioethanol from invasive macroalgae Sargassum muticum using autohydrolysis pretreatment as first step of a biorefinery. Renew. Energy 141, 728-735. https://doi.org/10.1016/j.renene.2019.03.083.

Diaz De Villegas, M.E., Villa, P., Guerra, M., Rodriguez, E., Redondo, D., Martinez, A., 1992. Conversion of Furfural into Furfuryl Alcohol by Saccharomyces cervisiae 354. Acta Biotechnol. 12, 351-354. https://doi.org/10.1002/abio.370120420.

Divate, N.R., Chen, G.-H., Divate, R.D., Ou, B.-R., Chung, Y.-C., 2017. Metabolic engineering of Saccharomyces cerevisiae for improvement in stresses tolerance. Bioengineered 8, 524-535. https://doi.org/10.1080/21655979.2016.1257449.

Domínguez, E., Romaní, A., Domingues, L., Garrote, G., 2017. Evaluation of strategies for second generation bioethanol production from fast growing biomass Paulownia within a biorefinery scheme. Appl. Energy 187, 777-789. https://doi.org/10.1016/j. apenergy.2016.11.114.

Drewke, C., Thielen, J., Ciriacy, M., 1990. Ethanol formation in adh 0 mutants reveals the existence of a novel acetaldehyde-reducing activity in Saccharomyces cerevisiae. J. Bacteriol. 172, 3909-3917. https://doi.org/10.1128/jb.172.7.3909-3917.1990.

Duvnjak, Z., Turcotte, G., Duan, Z.D., 1991a. Production of sorbitol and ethanol from Jerusalem artichokes by Saccharomyces cerevisiae ATCC 36859. Appl. Microbiol. Biotechnol. 35, 711-715. https://doi.org/10.1007/BF00169882.

Duvnjak, Z., Turcotte, G., Duan, Z.D., 1991b. Production and consumption of sorbitol and fructose by Saccharomyces cerevisiae ATCC 36859. J. Chem. Technol. Biotechnol. 52, 527-537. https://doi:10.1002/jctb.280520410.

Ferreira, R., Skrekas, C., Hedin, A., Sánchez, B.J., Siewers, V., Nielsen, J., David, F., 2019. Model-Assisted Fine-Tuning of Central Carbon Metabolism in Yeast through dCas9-Based Regulation. ACS Synth. Biol. 8 (11), 2457-2463. https://doi.org/ 10.1021/acssynbio.9b00258.

Gancedo, C., Gancedo, J.M., Sols, A., 1968. Glycerol Metabolism in Yeasts. Eur. J. Biochem. 5, 165-172. https://doi.org/10.1111/j.1432-1033.1968.tb00353.x.

Global Market Insights, 2020. Lactic Acid Market Size By Application (Industrial, Food \& Beverage, Pharmaceuticals, Personal Care), Polylactic Acid (PLA) Market Size By Application (Packaging, Agriculture, Transport, Electronics, Textiles), Industry Analysis Report, Regional Outlook, Application Potential, Price Trends, Competitive Market Share \& Forecast, 2020-2026. Available at: https://www.gminsights.com /industry-analysis/lactic-acid-and-polylactic-acid-market (Accessed: 29 October 2020).

Godan, T.K., Rajesh, R.O., Loreni, P.C., Kumar Rai, A., Sahoo, D., Pandey, A., Binod, P., 2019. Biotransformation of 5-hydroxymethylfurfural by Acinetobacter oleivorans S27 for the synthesis of furan derivatives. Bioresour. Technol. 282, 88-93. https://doi. org/10.1016/j.biortech.2019.02.125.

Gonzalez-Pajuelo, M., Meynial-Salles, I., Mendes, F., Andrade, J.C., Vasconcelos, I., Soucaille, P., 2005. Metabolic engineering of Clostridium acetobutylicum for the industrial production of 1,3-propanediol from glycerol. Metab. Eng. 7, 329-336. https://doi.org/10.1016/j.ymben.2005.06.001.

Görgens, J.F., Bressler, D.C., Van Rensburg, E., 2015. Engineering Saccharomyces cerevisiae for direct conversion of raw, uncooked or granular starch to ethanol. Crit. Rev. Biotechnol. https://doi.org/10.3109/07388551.2014.888048.

Gorsich, S.W., Dien, B.S., Nichols, N.N., Slininger, P.J., Liu, Z.L., Skory, C.D., 2006. Tolerance to furfural-induced stress is associated with pentose phosphate pathway genes ZWF1, GND1, RPE1, and TKL1 in Saccharomyces cerevisiae. Appl. Microbiol. Biotechnol. 71, 339-349. https://doi.org/10.1007/s00253-005-0142-3.

Govinden, R., Pillay, B., van Zyl, W.H., Pillay, D., 2001. Xylitol production by recombinant Saccharomyces cerevisiae expressing the Pichia stipitis and Candida shehatae XYL1 genes. Appl. Microbiol. Biotechnol. 55, 76-80. https://doi.org/ $10.1007 / \mathrm{s} 002530000455$.

Groot, W., van Krieken, J., Sliekersl, O., de Vos, S., 2010. Production and purification of lactic acid and lactide. In: Auras, R.A., Lim, L.T., Selke, S.E., Tsuji, H. (Eds.), Poly (lactic acid): Synthesis, Structures, Properties, Processing, and Applications. John Wiley \& Sons, New Jersey, USA, pp. 3-18.

Guenther, A., Karl, T., Harley, P., Wiedinmyer, C., Palmer, P.I., Geron, C., 2006. Estimates of global terrestrial isoprene emissions using MEGAN (Model of Emissions of Gases and Aerosols from Nature). Atmos. Chem. Phys. 6 (11), 3181-3210. https:// doi.org/10.5194/acp-6-3181-2006.

Guirimand, G., Sasaki, K., Inokuma, K., Bamba, T., Hasunuma, T., Kondo, A., 2016. Cell surface engineering of Saccharomyces cerevisiae combined with membrane separation technology for xylitol production from rice straw hydrolysate. Appl. Microbiol. Biotechnol. 100, 3477-3487. https://doi.org/10.1007/s00253-015-7179-8.

Guirimand, G., Inokuma, K., Bamba, T., Matsuda, M., Morita, K., Sasaki, K., Ogino, C., Berrin, J.-G., Hasunuma, T., Kondo, A., 2019a. Cell-surface display technology and metabolic engineering of Saccharomyces cerevisiae for enhancing xylitol production from woody biomass. Green Chem. 21, 1795-1808. https://doi.org/10.1039/ C8GC03864C.

Guirimand, G., Bamba, T., Matsuda, M., Inokuma, K., Morita, K., Kitada, Y., Kobayashi, Y., Yukawa, T., Sasaki, K., Ogino, C., Hasunuma, T., Kondo, A., 2019b. Combined Cell Surface Display of $\beta$-D-Glucosidase (BGL), Maltose Transporter (MAL11), and Overexpression of Cytosolic Xylose Reductase (XR) in Saccharomyces cerevisiae Enhance Cellobiose/Xylose Coutilization for Xylitol Bioproduction from
Lignocellulosi. Biotechnol. J. 14, e1800704 https://doi.org/10.1002/ biot. 201800704.

Hallborn, J., Walfridsson, M., Airaksinen, U., Ojamo, H., Hahn-Hägerdal, B., Penttilä, M., Keräsnen, S., 1991. Xylitol production by recombinant Saccharomyces cerevisiae. Biotechnology (N Y) 9, 1090-1095. https://doi.org/10.1038/nbt1191-1090.

Hallborn, J., Meinander, N., Hahn-Hägerdal, B., Gorwa, M.F., Pentillä, M., Keränen, S., 1994. The influence of cosubstrate and aeration on xylitol formation by recombinant Saccharomyces cerevisiae expressing the XYL1 gene. Appl. Microbiol. Biotechnol. 42, 326-333. https://doi.org/10.1007/BF00902737.

Hara, K.Y., Saito, M., Kato, H., Morikawa, K., Kikukawa, H., Nomura, H., Fujimoto, T., Hirono-Hara, Y., Watanabe, S., Kanamaru, K., Kondo, A., 2019. 5-Aminolevulinic acid fermentation using engineered Saccharomyces cerevisiae. Microb. Cell Factories 18, 194. https://doi.org/10.1186/s12934-019-1242-6.

Hasunuma, T., Ismail, K.S.K., Nambu, Y., Kondo, A., 2014. Co-expression of TAL1 and ADH1 in recombinant xylose-fermenting Saccharomyces cerevisiae improves ethanol production from lignocellulosic hydrolysates in the presence of furfural. J. Biosci. Bioeng. 117, 165-169.

Heer, D., Heine, D., Sauer, U., 2009. Resistance of Saccharomyces cerevisiae to High Concentrations of Furfural Is Based on NADPH-Dependent Reduction by at Least Two Oxireductases. Appl. Environ. Microbiol. 75, 7631-7638. https://doi.org/ 10.1128/aem.01649-09.

Hermann, B.G., Blok, K., Patel, M.K., 2007. Producing Bio-Based Bulk Chemicals Using Industrial Biotechnology Saves Energy and Combats Climate Change. Environ. Sci. Technol. 41 (22), 7915-7921. https://doi.org/10.1021/es062559q.

Hernandéz-Peréz, A.F., de Arruda, P.V., Sene, L., da Silva, S.S., Kumar Chandel, A., de Almeida Felipe, M., 2019. Xylitol bioproduction: state-of-the-art, industrial paradigm shift, and opportunities for integrated biorefineries. Crit. Rev. Biotechnol. 39, 924-943. https://doi.org/10.1080/07388551.2019.1640658.

Hohmann, S., 1991. Characterization of PDC6, a third structural gene for pyruvate decarboxylase in Saccharomyces cerevisiae. J. Bacteriol. 173 (24), 7963-7969. https://doi.org/10.1128/jb.173.24.7963-7969.1991.

Hong, K., Nielsen, J., 2012. Metabolic engineering of Saccharomyces cerevisiae: a key cell factory platform for future biorefineries. Cell. Mol. Life Sci. 69, 2671-2690. https:// doi.org/10.1007/s00018-012-0945-1.

Hong, S.-Y., Zurbriggen, A.S., Melis, A., 2012. Isoprene hydrocarbons production upon heterologous transformation of Saccharomyces cerevisiae. J. Appl. Microbiol. 113 (1), 52-65. https://doi.org/10.1111/j.1365-2672.2012.05319.x.

IEA Bioenergy, 2008. Sustainable and synergetic processing of biomass into marketable food \& feed ingredients, chemicals, materials and energy (fuels, power, heat). In: Bioenergy Task 42 on Biorefineries. Wageningen, Netherlands.

Igeño, M.I., Sánchez-Clemente, R., Población, A.G., Guijo, M.I., Merchán, F., Blasco, R., 2018. Biodegradation of 5-(Hydroxymethyl)-furfural and Furan Derivatives. Proceedings 2, 1283.

Ishii, J., Yoshimura, K., Hasunuma, T., Kondo, A., 2013. Reduction of furan derivatives by overexpressing NADH-dependent Adh1 improves ethanol fermentation using xylose as sole carbon source with Saccharomyces cerevisiae harboring XR-XDH pathway. Appl. Microbiol. Biotechnol. 97, 2597-2607. https://doi.org/10.1007/ s00253-012-4376-6.

Isikgor, F.H., Becer, C.R., 2015. Lignocellulosic biomass: a sustainable platform for the production of bio-based chemicals and polymers. Polym. Chem. 6, 4497-4559. https://doi.org/10.1039/C5PY00263J.

Islam, Z.-U., Klein, M., Asskamp, M.R., Odum, A.S.R., Nevoigt, E., 2017. A modular metabolic engineering approach for the production of 1,2-propanediol from glycerol by Saccharomyces cerevisiae. Metab. Eng. 44, 223-235. https://doi.org/10.1016/j. ymben.2017.10.002.

Ito, Y., Hirasawa, T., Shimizu, H., 2014. Metabolic engineering of Saccharomyces cerevisiae to improve succinic acid production based on metabolic profiling. Biosci. Biotechnol. Biochem. 78 (1), 151-159. https://doi.org/10.1080/ 09168451.2014.877816.

Jain, V.K., Divol, B., Prior, B.A., Bauer, F.F., 2011. Elimination of glycerol and replacement with alternative products in ethanol fermentation by Saccharomyces cerevisiae. J Ind Microbiol. Biotechnol. 38 (9), 1427-1435. https://doi.org/10.1007/ s10295-010-0928-x.

Janakiram, C., Deepan, Kumar, Joseph, C.V., 2017. Xylitol in preventing dental caries: A systematic review and meta-analyses. J. Nat. Sci. Biol. Med. 8, 16-21. https://doi. org/10.4103/0976-9668.198344.

Jansen, M.L.A., Bracher, J.M., Papapetridis, I., Verhoeven, M.D., de Bruijn, H., de Waal, P.P., van Maris, A.J.A., Klaassen, P., Pronk, J.T., 2017. Saccharomyces cerevisiae strains for second-generation ethanol production: from academic exploration to industrial implementation. FEMS Yeast Res. 17, 1-20. https://doi. org/10.1093/femsyr/fox044.

Jessop-Fabre, M.M., Jakočiūnas, T., Stovicek, V., Dai, Z., Jensen, M.K., Keasling, J.D., Borodina, I., 2016. EasyClone-MarkerFree: A vector toolkit for marker-less integration of genes into Saccharomyces cerevisiae via CRISPR-Cas9. Biotechnol. J. 11 (8), 1110-1117. https://doi.org/10.1002/biot.201600147.

Jesus, M.S., Romaní, A., Genisheva, Z., Teixeira, J.A., Domingues, L., 2017. Integral valorization of vine pruning residue by sequential autohydrolysis stages. J. Clean. Prod. 168, 74-86. https://doi.org/10.1016/j.jclepro.2017.08.230.

Ji, R.-Y., Ding, Y., Shi, T.-Q., Lin, L., Huang, H., Gao, Z., Ji, X.-J., 2018. Metabolic Engineering of Yeast for the Production of 3-Hydroxypropionic Acid. Front. Microbiol. 9, 1-7. https://doi.org/10.3389/fmicb.2018.02185.

Jin, Y.-S., Laplaza, J.M., Jeffries, T.W., 2004. Saccharomyces cerevisiae Engineered for Xylose Metabolism Exhibits a Respiratory Response. Appl. Environ. Microbiol. 70 (11), 6816-6825. https://doi.org/10.1128/AEM.70.11.6816-6825.2004. 
Jo, J.-H., Oh, S.-Y., Lee, H.-S., Park, Y.-C., Seo, J.-H., 2015. Dual utilization of NADPH and NADH cofactors enhances xylitol production in engineered Saccharomyces cerevisiae. Biotechnol. J. 10, 1935-1943. https://doi.org/10.1002/biot.201500068.

Jung, J.-Y., Yun, H.S., Lee, J., Oh, M.-K., 2011. Production of 1,2-propanediol from glycerol in Saccharomyces cerevisiae. J. Microbiol. Biotechnol. 21, 846-853. https:// doi.org/10.4014/jmb.1103.03009.

Kaur, G., Srivastava, A.K., Chand, S., 2012. Advances in biotechnological production of 1,3-propanediol. Biochem. Eng. J. 64, 106-118.

Kildegaard, K.R., Wang, Z., Chen, Y., Nielsen, J., Borodina, I., 2015. Production of 3hydroxypropionic acid from glucose and xylose by metabolically engineered Saccharomyces cerevisiae. Metab. Eng. Commun. 2, 132-136. https://doi.org/ 10.1016/j.meteno.2015.10.001.

Kildegaard, K.R., Jensen, N.B., Schneider, K., Czarnotta, E., Özdemir, E., Klein, T., Maury, J., Ebert, B.E., Christensen, H.B., Chen, Y., Kim, I.-K., Herrgård, M.J., Blank, L.M., Forster, J., Nielsen, J., Borodina, I., 2016. Engineering and systems-level analysis of Saccharomyces cerevisiae for production of 3-hydroxypropionic acid via malonyl-CoA reductase-dependent pathway. Microb. Cell Factories 15 (1), 53. https://doi.org/10.1186/s12934-016-0451-5.

Kim, T.-B., Lee, Y.-J., Kim, P., Kim, C.S., Oh, D.-K., 2004. Increased xylitol production rate during long-term cell recycle fermentation of Candida tropicalis. Biotechnol. Lett. 26, 623-627. https://doi.org/10.1023/b:bile.0000023019.02411.54.

Kim, H., Lee, H.-S., Park, H., Lee, D.-H., Boles, E., Chung, D., Park, Y.-C., 2017. Enhanced production of xylitol from xylose by expression of Bacillus subtilis arabinose: $\mathrm{H}^{+}$ symporter and Scheffersomyces stipitis xylose reductase in recombinant Saccharomyces cerevisiae. Enzym. Microb. Technol. 107, 7-14.

Kim, J., Jang, J.H., Yeo, H.J., Seol, J., Kim, S.R., Jung, Y.H., 2019. Lactic Acid Production from a Whole Slurry of Acid-Pretreated Spent Coffee Grounds by Engineered Saccharomyces cerevisiae. Appl. Biochem. Biotechnol. 189 (1), 206-216. https://doi. org/10.1007/s12010-019-03000-6.

Klein, M., Carrillo, M., Xiberras, J., Islam, Z., Swinnen, S., Nevoigt, E., 2016. Towards the exploitation of glycerol's high reducing power in Saccharomyces cerevisiae-based bioprocesses. Metab. Eng. 38, 464-472. https://doi.org/10.1016/j. ymben.2016.10.008.

Klein, M., Swinnen, S., Thevelein, J.M., Nevoigt, E., 2017. Glycerol metabolism and transport in yeast and fungi: established knowledge and ambiguities. Environ. Microbiol. 19, 878-893. https://doi.org/10.1111/1462-2920.13617.

Ko, J.K., Lee, S.-M., 2018. Advances in cellulosic conversion to fuels: engineering yeasts for cellulosic bioethanol and biodiesel production. Curr. Opin. Biotechnol. 50, 72-80. https://doi.org/10.1016/j.copbio.2017.11.007.

Ko, B.S., Rhee, C.H., Kim, J.H., 2006. Enhancement of xylitol productivity and yield using a xylitol dehydrogenase gene-disrupted mutant of Candida tropicalis under fully aerobic conditions. Biotechnol. Lett. 28, 1159-1162. https://doi.org/10.1007/ s10529-006-9068-9.

Kogje, A., Ghosalkar, A., 2016. Xylitol production by Saccharomyces cerevisiae overexpressing different xylose reductases using non-detoxified hemicellulosic hydrolysate of corncob. Biotech 3, 6-127. https://doi.org/10.1007/s13205-0160444-4.

Kogje, A.B., Ghosalkar, A., 2017. Xylitol production by genetically modified industrial strain of Saccharomyces cerevisiae using glycerol as co-substrate. J. Ind. Microbiol. Biotechnol. 44, 961-971. https://doi.org/10.1007/s10295-017-1914-3.

Koopman, F., Wierckx, N., de Winde, J.H., Ruijssenaars, H.J., 2010. Identification and characterization of the furfural and 5-(hydroxymethyl)furfural degradation pathways of Cupriavidus basilensis HMF14. Proc. Natl. Acad. Sci. U. S. A. 107, 4919-4924. https://doi.org/10.1073/pnas.0913039107.

Kötter, P., Ciriacy, M., 1993. Xylose fermentation by Saccharomyces cerevisiae. Appl. Microbiol. Biotechnol. 38, 776-783. https://doi.org/10.1007/BF00167144.

Kubo, Y., Takagi, H., Nakamori, S., 2000. Effect of gene disruption of succinate dehydrogenase on succinate production in a sake yeast strain. J. Biosci. Bioeng. 90 (6), 619-624. https://doi.org/10.1016/S1389-1723(00)90006-9.

Kumar, V., Ashok, S., Park, S., 2013. Recent advances in biological production of 3hydroxypropionic acid. Biotechnol. Adv. 31, 945-961. https://doi.org/10.1016/j. biotechadv.2013.02.008.

Kumar, L.R., Yellapu, S.K., Tyagi, R.D., Zhang, X., 2019. A review on variation in crude glycerol composition, bio-valorization of crude and purified glycerol as carbon source for lipid production. 293, 122155. doi:doi:10.1016/j.biortech.2019.122155. Bioresour. Technol. 293, 122155.

Kumar, R., Basak, B., Jeon, B.-H., 2020a. Sustainable production and purification of succinic acid: A review of membrane-integrated green approach. J. Clean. Prod. 277, 123954. https://doi.org/10.1016/j.jclepro.2020.123954.

Kumar, A., Shende, D.Z., Wasewar, K.L., 2020b. Production of levulinic acid: A promising building block material for pharmaceutical and food industry. Materials Today: Proceedings 29, 790-793.

Kuzma, J., Nemecek-Marshall, M., Pollock, W.H., Fall, R., 1995. Bacteria produce the volatile hydrocarbon isoprene. Curr. Microbiol. 30 (2), 97-103. https://doi.org/ 10.1007/BF00294190.

Kwon, S.-G., Park, S.-W., Oh, D.-K., 2006. Increase of xylitol productivity by cell-recycle fermentation of Candida tropicalis using submerged membrane bioreactor. J. Biosci. Bioeng. 101, 13-18. https://doi.org/10.1263/jbb.101.13.

Laadan, B., Almeida, J.R.M., Rådström, P., Hahn-Hägerdal, B., Gorwa-Grauslund, M., 2008. Identification of an NADH-dependent 5-hydroxymethylfurfural-reducing alcohol dehydrogenase in Saccharomyces cerevisiae. Yeast 25, 191-198. https://doi. org/10.1002/yea.1578.

Ladero, V., Ramos, A., Wiersma, A., Goffin, P., Schanck, A., Kleerebezem, M., Hugenholtz, J., Smid, E.J., Hols, P., 2007. High-Level Production of the Low-Calorie Sugar Sorbitol by Lactobacillus plantarum through Metabolic Engineering. Appl. Environ. Microbiol. 73, 1864-1872. https://doi.org/10.1128/AEM.02304-06.
Lane, S., Xu, H., Oh, E.J., Kim, H., Lesmana, A., Jeong, D., Zhang, G., Tsai, C.-S., Jin, Y.S., Kim, S.R., 2018. Glucose repression can be alleviated by reducing glucose phosphorylation rate in Saccharomyces cerevisiae. Sci. Rep. 8, 2613. https://doi.org/ 10.1038/s41598-018-20804-4.

Larsson, S., Cassland, P., Jönsson, L.J., 2001. Development of a Saccharomyces cerevisiae Strain with Enhanced Resistance to Phenolic Fermentation Inhibitors in Lignocellulose Hydrolysates by Heterologous Expression of Laccase. Appl. Environ. Microbiol. 67, 1163-1170. https://doi.org/10.1128/AEM.67.3.1163-1170.2001.

Lasure, L.L., Zhang, M., 2003. Bioconversion and Biorefineries of the Future. In: Applications of Biotechnology to Mitigation of Greenhouse Warming: Proceedings of the St. Michaels II Workshop, pp. 95-109.

Lee, W.-J., Ryu, Y.-W., Seo, J.-H., 2000. Characterization of two-substrate fermentation processes for xylitol production using recombinant Saccharomyces cerevisiae containing xylose reductase gene. Process Biochem. 35, 1199-1203.

Lee, J.Y., Kang, C.D., Lee, S.H., Park, Y.K., Cho, K.M., 2015. Engineering cellular redox balance in Saccharomyces cerevisiae for improved production of L-lactic acid. Biotechnol. Bioeng. 112 (4), 751-758. https://doi.org/10.1002/bit.25488.

Lee, J.J., Crook, N., Sun, J., Alper, H.S., 2016. Improvement of lactic acid production in Saccharomyces cerevisiae by a deletion of ssb1. J. Ind. Microbiol. Biotechnol. 43 (1), 87-96. https://doi.org/10.1007/s10295-015-1713-7.

Li, S., Si, T., Wang, M., Zhao, H., 2015. Development of a Synthetic Malonyl-CoA Sensor in Saccharomyces cerevisiae for Intracellular Metabolite Monitoring and Genetic Screening. ACS Synth. Biol. 4 (12), 1308-1315. https://doi.org/10.1021/ acssynbio.5b00069.

Li, Y., Wang, X., Ge, X., Tian, P., 2016. High Production of 3-Hydroxypropionic Acid in Klebsiella pneumoniae by Systematic Optimization of Glycerol Metabolism. Sci. Rep. 6 (1), 26932. https://doi.org/10.1038/srep26932.

Li, C., Yang, X., Gao, S., Wang, H., Lin, C.S.K., 2017. High efficiency succinic acid production from glycerol via in situ fibrous bed bioreactor with an engineered Yarrowia lipolytica. Bioresour. Technol. 225, 9-16. https://doi.org/10.1016/j. biortech.2016.11.016.

Lian, J., Bao, Z., Hu, S., Zhao, H., 2018. Engineered CRISPR/Cas9 system for multiplex genome engineering of polyploid industrial yeast strains. Biotechnol. Bioeng. 115 (6), 1630-1635. https://doi.org/10.1002/bit.26569.

Lis, A.V., Schneider, K., Weber, J., Keasling, J.D., Jensen, M.K., Klein, T., 2019. Exploring small-scale chemostats to scale up microbial processes: 3-hydroxypropionic acid production in S. cerevisiae. , 18(1), 50. Microb. Cell Factories 18 (1), 50. https://doi. org/10.1186/s12934-019-1101-5.

Litsanov, B., Brocker, M., Bott, M., 2012. Toward Homosuccinate Fermentation: Metabolic Engineering of Corynebacterium glutamicum for Anaerobic Production of Succinate from Glucose and Formate. Appl. Environ. Microbiol. 78 (9), 3325-3337. https://doi.org/10.1128/AEM.07790-11.

Liu, Z.L., Moon, J., 2009. A novel NADPH-dependent aldehyde reductase gene from Saccharomyces cerevisiae NRRL Y-12632 involved in the detoxification of aldehyde inhibitors derived from lignocellulosic biomass conversion. Gene 446, 1-10.

Liu, Z.L., Slininger, P.J., Dien, B.S., Berhow, M.A., Kurtzman, C.P., Gorsich, S.W., 2004. Adaptive response of yeasts to furfural and 5-hydroxymethylfurfural and new chemical evidence for HMF conversion to 2,5-bis-hydroxymethylfuran. J. Ind. Microbiol. Biotechnol. 31, 345-352. https://doi.org/10.1007/s10295-004-0148-3.

Liu, Z.L., Slininger, P.J., Gorsich, S.W., 2005. Enhanced biotransformation of furfural and hydroxymethylfurfural by newly developed ethanologenic yeast strains. Appl. Biochem. Biotechnol. 121, 451-460. https://doi.org/10.1385/ABAB:121:1-3:0451.

Liu, Z.L., Moon, J., Andersh, B.J., Slininger, P.J., Weber, S., 2008. Multiple genemediated NAD(P)H-dependent aldehyde reduction is a mechanism of in situ detoxification of furfural and 5-hydroxymethylfurfural by Saccharomyces cerevisiae. Appl. Microbiol. Biotechnol. 81, 743-753. https://doi.org/10.1007/s00253-0081702-0.

Luo, Y., Li, Z., Li, X., Liu, X., Fan, J., Clark, J.H., Hu, C., 2019. The production of furfural directly from hemicellulose in lignocellulosic biomass: A review. Catal. Today 319, 14-24.

Lv, X., Xie, W., Lu, W., Guo, F., Gu, J., Yu, H., Ye, L., 2014. Enhanced isoprene biosynthesis in Saccharomyces cerevisiae by engineering of the native acetyl-CoA and mevalonic acid pathways with a push-pull-restrain strategy. J. Biotechnol. 186, 128-136. https://doi.org/10.1016/j.jbiotec.2014.06.024.

Lv, X., Wang, F., Zhou, P., Ye, L., Xie, W., Xu, H., Yu, H., 2016. Dual regulation of cytoplasmic and mitochondrial acetyl-CoA utilization for improved isoprene production in Saccharomyces cerevisiae. Nat. Commun. 7 (1), 12851. https://doi.org/ 10.1038/ncomms12851.

Mancini, E., Mansouri, S.S., Gernaey, K.V., Luo, J., Pinelo, M., 2019. From second generation feed-stocks to innovative fermentation and downstream techniques for succinic acid production. Crit. Rev. Environ. Sci. Technol. 1-45. https://doi.org/ 10.1080/10643389.2019.1670530.

Mandalika, A., Qin, L., Sato, T.K., Runge, T., 2014. Integrated biorefinery model based on production of furans using open-ended high yield processes. Green Chem. 16, 2480-2489. https://doi.org/10.1039/C3GC42424C.

Market Research Future, 2020. Global Isoprene Market: Information by Grade (Polymer Grade and Chemical Grade), Application (Styrene Isoprene Styrene, Isobutylene Isoprene, Polyisoprene, Block Co-Polymer, and Others), End-Use Industry (Automotive, Medical, Construction, Personal Care, Sports \& Leisure, and Others), and Region (North America, Europe, Asia-Pacific, Latin America, and Middle East \& Africa)—Forecast till 2025. Available at: https://www.marketresearchfuture.com/r eports/isoprene-industry-4799 (Accessed: 29 October 2020).

Market Study Report, 2019. Global 5-hydroxymethylfurfural (5-HMF) (CAS 67-47-0) Market 2019 by Manufacturers, Regions, Type and Application, Forecast to 2024. GlobalInfoResearch Available at: https://www.marketstudyreport.com/reports/glob 
al-5-hydroxymethylfurfural-5-hmf-cas-67-47-0-market-2019-by-manufacturers-re gions-type-and-application-forecast-to-2024 (Accessed: 31 July 2020).

Markets and Markets, 2019. Furfural Market by Raw Material (Sugarcane Bagasse, Corncob, Rice Husk and Others), Application (Derivatives (Furfural Alcohol and Other Derivatives), solvent) and Region (Asia-Pacific, Americas, Europe,Middle East and Africa) - Global Forecast to 2024. Available at: https://www.marketsandmarket s.com/Market-Reports/furfural-market-101056456.html (Accessed: 31 July 2020).

Matsakas, L., Hrůzová, K., Rova, U., Christakopoulos, P., 2018. Biological Production of 3-Hydroxypropionic Acid: An Update on the Current Status. Fermentation 4 (1), 13. https://doi.org/10.3390/fermentation4010013.

Maury, J., Kannan, S., Jensen, N.B., Öberg, F.K., Kildegaard, K.R., Forster, J., Nielsen, J. Workman, C.T., Borodina, I., 2018. Glucose-Dependent Promoters for Dynamic Regulation of Metabolic Pathways. Front. Bioeng. Biotechnol. 6, 1-12. https://doi. org/10.3389/fbioe.2018.00063.

Mes-Hartree, M., Dale, B.E., Craig, W.K., 1988. Comparison of steam and ammonia pretreatment for enzymatic hydrolysis of cellulose. Appl. Microbiol. Biotechnol. 29, 462-468. https://doi.org/10.1007/BF00269069.

Michnick, S., Roustan, J.L., Remize, F., Barre, P., Dequin, S., 1997. Modulation of glycerol and ethanol yields during alcoholic fermentation in Saccharomyces cerevisiae strains overexpressed or disrupted for GPDI encoding glycerol 3-phosphate dehydrogenase. Yeast 13, 783-793. https://doi.org/10.1002/(SICI)1097-0061 (199707)13:9<783::AID-YEA128>3.0.CO;2-W.

Mira, N.P., Teixeira, M.C., Sá-Correia, I., 2010. Adaptive response and tolerance to weak acids in Saccharomyces cerevisiae: A genome-wide view. Omi. A J. Integr. Biol. https://doi.org/10.1089/omi.2010.0072.

Moon, J., Liu, Z.L., 2012. Engineered NADH-dependent GRE2 from Saccharomyces cerevisiae by directed enzyme evolution enhances HMF reduction using additional cofactor NADPH. Enzym. Microb. Technol. 50, 115-120.

Morais, E.S., Freire, M.G., Freire, C.S.R., Coutinho, J.A.P., Silvestre, A.J.D., 2020. Enhanced Conversion of Xylan into Furfural using Acidic Deep Eutectic Solvents with Dual Solvent and Catalyst Behavior. ChemSusChem 13, 784-790. https://doi. org /10.1002/cssc.201902848.

Morone, A., Apte, M., Pandey, R.A., 2015. Levulinic acid production from renewable waste resources: Bottlenecks, potential remedies, advancements and applications. Renew. Sust. Energ. Rev. 51, 548-565. https://doi.org/10.1016/j.rser.2015.06.032.

Murashchenko, L., Abbas, C., Dmytruk, K., Sibirny, A., 2016. Overexpression of the truncated version of ILV2 enhances glycerol production in Saccharomyces cerevisiae. Yeast 33, 463-469. https://doi.org/10.1002/yea.3161.

Murrell, J.C., McGenity, T.J., Crombie, A.T., 2020. Microbial metabolism of isoprene: a much-neglected climate-active gas. Microbiology 166 (7), 600-613. https://doi.org/ 10.1099/mic.0.000931.

Muzumdar, A.V., Sawant, S.B., Pangarkar, V.G., 2004. Reduction of Maleic Acid to Succinic Acid on Titanium Cathode. Org. Process Res. Dev. 8 (4), 685-688. https:// doi.org/10.1021/op0300185.

Nevoigt, E., Stahl, U., 1996. Reduced pyruvate decarboxylase and increased glycerol-3phosphate dehydrogenase $\left[\mathrm{NAD}^{+}\right]$levels enhance glycerol production in Saccharomyces cerevisiae. Yeast 12, 1331-1337. https://doi.org/10.1002/(SICI) 1097-0061(199610)12:13<1331::AID-YEA28>3.0.CO;2-0.

Nielsen, J., Jewett, M.C., 2008. Impact of systems biology on metabolic engineering of Saccharomyces cerevisiae. FEMS Yeast Res. 8, 122-131. https://doi.org/10.1111/ j.1567-1364.2007.00302x.

Nijland, J.G., Driessen, A.J.M., 2020. Engineering of Pentose Transport in Saccharomyces cerevisiae for Biotechnological Applications. Front. Bioeng. Biotechnol. 7 https://doi org/10.3389/fbioe.2019.00464.

Novy, V., Brunner, B., Müller, G., Nidetzky, B., 2017. Toward "homolactic" fermentation of glucose and xylose by engineered Saccharomyces cerevisiae harboring a kinetically efficient 1 -lactate dehydrogenase within $p d c 1-p d c 5$ deletion background. Biotechnol. Bioeng. 114 (1), 163-171. https://doi.org/10.1002/bit.26048.

Novy, V., Brunner, B., Nidetzky, B., 2018. L-Lactic acid production from glucose and xylose with engineered strains of Saccharomyces cerevisiae: aeration and carbon source influence yields and productivities. Microb. Cell Factories 17 (1), 59. https:// doi.org/10.1186/s12934-018-0905-z.

Oh, Y.-J., Lee, T.-H., Lee, S.-H., Oh, E.-J., Ryu, Y.-W., Kim, M.-D., Seo, J.-H., 2007. Dual modulation of glucose 6-phosphate metabolism to increase NADPH-dependent xylitol production in recombinant Saccharomyces cerevisiae. J. Mol. Catal. B Enzym. $47,37-42$.

Oh, E.J., Ha, S.-J., Rin Kim, S., Lee, W.-H., Galazka, J.M., Cate, J.H.D., Jin, Y.-S., 2013 Enhanced xylitol production through simultaneous co-utilization of cellobiose and xylose by engineered Saccharomyces cerevisiae. Metab. Eng. 15, 226-234. https://doi. org/10.1016/j.ymben.2012.09.003.

Okino, S., Noburyu, R., Suda, M., Jojima, T., Inui, M., Yukawa, H., 2008. An efficient succinic acid production process in a metabolically engineered Corynebacterium glutamicum strain. Appl. Microbiol. Biotechnol. 81 (3), 459-464. https://doi.org/ 10.1007/s00253-008-1668-y.

Otero, J.M., Cimini, D., Patil, K.R., Poulsen, S.G., Olsson, L., Nielsen, J., 2013. Industrial Systems Biology of Saccharomyces cerevisiae Enables Novel Succinic Acid Cell Factory. PLoS One 8 (1), e54144. https://doi.org/10.1371/journal.pone.0054144.

Overkamp, K.M., Bakker, B.M., Kötter, P., Luttik, M.A.H., Van Dijken, J.P., Pronk, J.T. 2002. Metabolic engineering of glycerol production in Saccharomyces cerevisiae. Appl. Environ. Microbiol. 68, 2814-2821. https://doi.org/10.1128/aem.68.6.28142821.2002.

Palmqvist, E., Hahn-Hagerdal, B., 2000. Fermentation of lignocellulosic hydrolysates. II: inhibitors and mechanisms of inhibition. Bioresour. Technol. 74, 25-33. https://doi. org/10.1016/S0960-8524(99)00161-3.

Park, S.-E., Koo, H.M., Park, Y.K., Park, S.M., Park, J.C., Lee, O.-K., Park, Y.-C., Seo, J.-H., 2011. Expression of aldehyde dehydrogenase 6 reduces inhibitory effect of furan derivatives on cell growth and ethanol production in Saccharomyces cerevisiae. Bioresour. Technol. 102, 6033-6038.

Peleteiro, S., Rivas, S., Alonso, J.L., Santos, V., Parajó, J.C., 2016. Furfural production using ionic liquids: A review. Bioresour. Technol. 202, 181-191.

Peralta-Yahya, P.P., Keasling, J.D., 2010. Advanced biofuel production in microbes. Biotechnol. J. 5 (2), 147-162. https://doi.org/10.1002/biot.200900220.

Pereira, F.B., Guimarães, P.M., Teixeira, J.A., Domingues, L., 2010. Selection of Saccharomyces cerevisiae strains for efficient very high gravity bio-ethanol fermentation processes. Biotechnol. Lett. 32, 1655-1661. https://doi.org/10.1007/ s10529-010-0330-9.

Pereira, F.B., Guimarães, P.M.R., Teixeira, J.A., Domingues, L., 2011. Robust industrial Saccharomyces cerevisiae strains for very high gravity bio-ethanol fermentations. J. Biosci. Bioeng. 112 (2), 130-136. https://doi.org/10.1016/j.jbiosc.2011.03.022.

Pereira, F.B., Romani, A., Ruiz, H.A., Teixeira, J.A., Domingues, L., 2014. Industrial robust yeast isolates with great potential for fermentation of lignocellulosic biomass. Bioresour. Technol. 161, 192-199. https://doi.org/10.1016/j.biortech.2014.03.043.

Petersson, A., Almeida, J.R.M., Modig, T., Karhumaa, K., Hahn-Hägerdal, B., GorwaGrauslund, M.F., Lidén, G., 2006. A 5-hydroxymethyl furfural reducing enzyme encoded by the Saccharomyces cerevisiae ADH6 gene conveys HMF tolerance. Yeast 23, 455-464. https://doi.org/10.1002/yea.1370.

PR Newswire, 2020. Bio-Succinic Acid Market Size is Expected to Grow at a CAGR of $15.7 \%$ - Valuates Reports. Available at: https://www.prnewswire.com/news-release s/bio-succinic-acid-market-size-is-expected-to-grow-at-a-cagr-of-15-7-valuates-rep orts-301116323.html\#: :text=The\%20Global\%20bio\%20succinic $\% 20$ acid,the $\%$ 20 forecast $\% 20$ period $\% 202020 \% 2 D 2026$. (Accessed: 29 October 2020).

Quehenberger, J., Reichenbach, T., Baumann, N., Rettenbacher, L., Divne, C., Spadiut, O., 2019. Kinetics and Predicted Structure of a Novel Xylose Reductase from Chaetomium thermophilum. Int. J. Mol. Sci. 20 https://doi.org/10.3390/ ijms 20010185 .

Raab, A.M., Gebhardt, G., Bolotina, N., Weuster-Botz, D., Lang, C., 2010. Metabolic engineering of Saccharomyces cerevisiae for the biotechnological production of succinic acid. Metab. Eng. 12 (6), 518-525. https://doi.org/10.1016/j. ymben.2010.08.005.

Rajesh, R.O., Godan, T.K., Rai, A.K., Sahoo, D., Pandey, A., Binod, P., 2019. Biosynthesis of 2,5-furan dicarboxylic acid by Aspergillus flavus APLS-1: Process optimization and intermediate product analysis. Bioresour. Technol. 284, 155-160.

Remize, F., Barnavon, L., Dequin, S., 2001. Glycerol export and glycerol-3-phosphate dehydrogenase, but not glycerol phosphatase, are rate limiting for glycerol production in Saccharomyces cerevisiae. Metab. Eng. 3, 301-312. https://doi.org/ 10.1006/mben.2001.0197.

Romaní, A., Ruiz, H.A., Pereira, F.B., Teixeira, J.A., Domingues, L., 2014. Integrated approach for effective bioethanol production using whole slurry from autohydrolyzed Eucalyptus globulus wood at high-solid loadings, 135, pp. 482-491. https://doi.org/10.1016/j.fuel.2014.06.061.

Romaní, A., Pereira, F., Johansson, B., Domingues, L., 2015. Metabolic engineering of Saccharomyces cerevisiae ethanol strains PE-2 and CAT-1 for efficient lignocellulosic fermentation. Bioresour. Technol. 179, 150-158. https://doi.org/10.1016/j. biortech.2014.12.020.

Romaní, A., Ruiz, H.A., Teixeira, J.A., Domingues, L., 2016a. Valorization of Eucalyptus wood by glycerol-organosolv pretreatment within the biorefinery concept: An integrated and intensified approach. Renew. Energy 95, 1-9. https://doi.org/ 10.1016/j.renene.2016.03.106.

Romaní, A., Tomaz, P.D., Garrote, G., Teixeira, J.A., Domingues, L., 2016b. Combined alkali and hydrothermal pretreatments for oat straw valorization within a biorefinery concept. Bioresour. Technol. 220, 323-332. https://doi.org/10.1016/j. biortech.2016.08.077.

Romaní, A., Morais, E.S., Soares, P.O., Freire, M.G., Freire, C.S.R., Silvestre, A.J.D., Domingues, L., 2020. Aqueous solutions of deep eutectic systems as reaction media for the saccharification and fermentation of hardwood xylan into xylitol. Bioresour. Technol. 311, 123524. https://doi.org/10.1016/j.biortech.2020.123524.

Rosales-Calderon, O., Arantes, V., 2019. A review on commercial-scale high-value products that can be produced alongside cellulosic ethanol. Biotechnol. Biofuels 12, 240. https://doi.org/10.1186/s13068-019-1529-1.

Ryu, A.J., Kim, T.Y., Yang, D.S., Park, J.H., Jeong, K.J., 2018. Engineering of Saccharomyces cerevisiae for enhanced production of L-lactic acid by co-expression of acid-stable glycolytic enzymes from Picrophilus torridus. Korean J. Chem. Eng. 35 (8), 1673-1679. https://doi.org/10.1007/s11814-018-0069-x.

Salli, K., Lehtinen, M.J., Tiihonen, K., Ouwehand, A.C., 2019. Xylitol's Health Benefits beyond Dental Health: A Comprehensive Review. Nutrients 11, 1813. https://doi. org/10.3390/nu11081813.

Sarthy, A.V., Schopp, C., Idler, K.B., 1994. Cloning and sequence determination of the gene encoding sorbitol dehydrogenase from Saccharomyces cerevisiae. Gene 140 121-126. https://doi.org/10.1016/0378-1119(94)90741-2.

Sasaki, K., Watanabe, M., Tanaka, T., Tanaka, T., 2002. Biosynthesis, biotechnological production and applications of 5-aminolevulinic acid. Appl. Microbiol. Biotechnol. 58 (1), 23-29. https://doi.org/10.1007/s00253-001-0858-7.

Sauer, M., Porro, D., Mattanovich, D., Branduardi, P., 2008. Microbial production of organic acids: expanding the markets. Trends Biotechnol. 26 (2), 100-108. https:// doi.org/10.1016/j.tibtech.2007.11.006.

Semkiv, M.V., Dmytruk, K.V., Abbas, C.A., Sibirny, A.A., 2017. Metabolic engineering for high glycerol production by the anaerobic cultures of Saccharomyces cerevisiae. Appl. Microbiol. Biotechnol. 101, 4403-4416. https://doi.org/10.1007/s00253-017-8202-

Shi, S., Chen, Y., Siewers, V., Nielsen, J., 2014. Improving Production of Malonyl Coenzyme A-Derived Metabolites by Abolishing Snf1-Dependent Regulation of Acc1. MBio 5 (3). https://doi.org/10.1128/mBio.01130-14 e01130-14. 
Signoretto, M., Taghavi, S., Ghedini, E., Menegazzo, F., 2019. Catalytic Production of Levulinic Acid (LA) from Actual Biomass. Molecules 24 (15), 2760. https://doi.org/ 10.3390/molecules24152760.

Silveira, M.M., Jonas, R., 2002. The biotechnological production of sorbitol. Appl. Microbiol. Biotechnol. 59, 400-408. https://doi.org/10.1007/s00253-002-1046-0.

Steinbach, D., Kruse, A., Sauer, J., 2017. Pretreatment technologies of lignocellulosic biomass in water in view of furfural and 5-hydroxymethylfurfural production- A review. Biomass Convers. Biorefinery 7, 247-274. https://doi.org/10.1007/s13399017-0243-0.

Stovicek, V., Borodina, I., Forster, J., 2015. CRISPR-Cas system enables fast and simple genome editing of industrial Saccharomyces cerevisiae strains. Metabolic Engineering Communications 2, 13-22. https://doi.org/10.1016/j.meteno.2015.03.001.

Subtil, T., Boles, E., 2012. Competition between pentoses and glucose during uptake and catabolism in recombinant Saccharomyces cerevisiae. Biotechnol. Biofuels 5, 14. https://doi.org/10.1186/1754-6834-5-14.

Sugiyama, M., Akase, S., Nakanishi, R., Kaneko, Y., Harashima, S., 2016. Overexpression of ESBP6 improves lactic acid resistance and production in Saccharomyces cerevisiae. J. Biosci. Bioeng. 122 (4), 415-420. https://doi.org/10.1016/j.jbiosc.2016.03.010.

Sweygers, N., Harrer, J., Dewil, R., Appels, L., 2018. A microwave-assisted process for the in-situ production of 5-hydroxymethylfurfural and furfural from lignocellulosic polysaccharides in a biphasic reaction system. J. Clean. Prod. 187, 1014-1024. https://doi.org/10.1016/j.jclepro.2018.03.204.

Swinnen, S., Ho, P.-W., Klein, M., Nevoigt, E., 2016. Genetic determinants for enhanced glycerol growth of Saccharomyces cerevisiae. Metab. Eng. 36, 68-79. https://doi.org/ 10.1016/j.ymben.2016.03.003.

Taherzadeh, M.J., Gustafsson, L., Niklasson, C., Lidén, G., 1999. Conversion of furfural in aerobic and anaerobic batch fermentation of glucose by Saccharomyces cerevisiae. J. Biosci. Bioeng. 87, 169-174.

Taherzadeh, M.J., Gustafsson, L., Niklasson, C., Lidén, G., 2000. Physiological effects of 5-hydroxymethylfurfural on Saccharomyces cerevisiae. Appl. Microbiol. Biotechnol. 53, 701-708. https://doi.org/10.1007/s002530000328.

Takkellapati, S., Li, T., Gonzalez, M.A., 2018. An overview of biorefinery-derived platform chemicals from a cellulose and hemicellulose biorefinery. Clean Techn. Environ. Policy 20, 1615-1630. https://doi.org/10.1007/s10098-018-1568-5.

Tan, H.W., Abdul Aziz, A.R., Aroua, M.K., 2013. Glycerol production and its applications as a raw material: A review. Renew. Sust. Energ. Rev. https://doi.org/10.1016/j. rser.2013.06.035.

Tomás-Pejó, E., Oliva, J.M., Ballesteros, M., Olsson, L., 2008. Comparison of SHF and SSF processes from steam-exploded wheat straw for ethanol production by xylosefermenting and robust glucose-fermenting Saccharomyces cerevisiae strains. Biotechnol. Bioeng. 100, 1122-1131. https://doi.org/10.1002/bit.21849.

Turner, T.L., Zhang, G.-C., Kim, S.R., Subramaniam, V., Steffen, D., Skory, C.D., Jang, J. Y., Yu, B.J., Jin, Y.-S., 2015. Lactic acid production from xylose by engineered Saccharomyces cerevisiae without PDC or ADH deletion. Appl. Microbiol. Biotechnol. 99 (19), 8023-8033. https://doi.org/10.1007/s00253-015-6701-3.

Turner, T.L., Zhang, G.-C., Oh, E.J., Subramaniam, V., Adiputra, A., Subramaniam, V., Skory, C.D., Jang, J.Y., Yu, B.J., Park, I., Jin, Y.-S., 2016. Lactic acid production from cellobiose and xylose by engineered Saccharomyces cerevisiae. Biotechnol. Bioeng. 113 (5), 1075-1083. https://doi.org/10.1002/bit.25875.

Turner, T.L., Kim, E., Hwang, C., Zhang, G.-C., Liu, J.-J., Jin, Y.-S., 2017. Short communication: Conversion of lactose and whey into lactic acid by engineered yeast. J. Dairy Sci. 100 (1), 124-128. https://doi.org/10.3168/jds.2016-11784.

van der Werf, M.J., Zeikus, J.G., 1996. 5-Aminolevulinate production by Escherichia coli containing the Rhodobacter sphaeroides hemA gene. Appl. Environ. Microbiol. 62 (10), 3560-3566. https://doi.org/10.1128/AEM.62.10.3560-3566.1996.

van Maris, A.J.A., Winkler, A.A., Porro, D., van Dijken, J.P., Pronk, J.T., 2004. Homofermentative Lactate Production Cannot Sustain Anaerobic Growth of Engineered Saccharomyces cerevisiae: Possible Consequence of Energy-Dependent Lactate Export. Appl. Environ. Microbiol. 70 (5), 2898-2905. https://doi.org/ 10.1128/AEM.70.5.2898-2905.2004.

Verwaal, R., Buiting-Wiessenhaan, N., Dalhuijsen, S., Roubos, J.A., 2018. CRISPR/Cpf1 enables fast and simple genome editing of Saccharomyces cerevisiae. Yeast 35, 201-211. https://doi.org/10.1002/yea.3278.

Villa, G.P., Bartroli, R., López, R., Guerra, M., Enrique, M., Peñas, M., Rodríquez, E., Redondo, D., Jglesias, I., Díaz, M., 1992. Microbial transformation of furfural to furfuryl alcohol by Saccharomyces cerevisiae. Acta Biotechnol. 12, 509-512. https:// doi.org/10.1002/abio.370120613.
Wang, Z., Zhuge, J., Fang, H., Prior, B., 2001. Glycerol production by microbial fermentation: a review. Biotechnol. Adv. 19, 201-223. https://doi.org/10.1016/ S0734-9750(01)00060-X.

Wang, D., Li, Q., Song, Z., Zhou, W., Su, Z., Xing, J., 2011. High cell density fermentation via a metabolically engineered Escherichia coli for the enhanced production of succinic acid. J. Chem. Technol. Biotechnol. 86 (4), 512-518. https://doi.org/ $10.1002 /$ jctb. 2543 .

Wang, C., Shen, Y., Hou, J., Suo, F., Bao, X., 2013. An assay for functional xylose transporters in Saccharomyces cerevisiae. Anal. Biochem. 442, 241-248. https://doi. org/10.1016/j.ab.2013.07.041.

Wang, F., Lv, X., Xie, W., Zhou, P., Zhu, Y., Yao, Z., Yang, C., Yang, X., Ye, L., Yu, H., 2017. Combining Gal4p-mediated expression enhancement and directed evolution of isoprene synthase to improve isoprene production in Saccharomyces cerevisiae. Metab. Eng. 39, 257-266. https://doi.org/10.1016/j.ymben.2016.12.011.

Wei, W., Wu, K., Qin, Y., Xie, Z., Zhu, X., 2001. Intergeneric protoplast fusion between Kluyveromyces and Saccharomyces cerevisiae - to produce sorbitol from Jerusalem artichokes. Biotechnol. Lett. 23, 799-803. https://doi.org/10.1023/A: 1010310601876.

Weissermel, K., Arpe, H.-J., 1992. Industrial Organic Chemistry. John Wiley \& Sons.

Werpy, T., Petersen, G., 2004. Top Value Added Chemicals from Biomass: Volume I Results of Screening for Potential Candidates from Sugars and Synthesis Gas, Us Nrel. Golden, CO (United States). https://doi.org/10.2172/15008859.

Wu, L., Moteki, T., Gokhale, A.A., Flaherty, D.W., Toste, F.D., 2016. Production of Fuels and Chemicals from Biomass: Condensation Reactions and Beyond. Chem 1, 32-58. https://doi.org/10.1016/j.chempr.2016.05.002.

Xia, Z.H., Zong, M.H., Li, N., 2020. Catalytic synthesis of 2,5-bis(hydroxymethyl)furan from 5-hydroxymethylfurfual by recombinant Saccharomyces cerevisiae. Enzym. Microb. Technol. 134, 109491. https://doi.org/10.1016/j.enzmictec.2019.109491.

Xiberras, J., Klein, M., de Hulster, E., Mans, R., Nevoigt, E., 2020. Engineering Saccharomyces cerevisiae for Succinic Acid Production From Glycerol and Carbon Dioxide. Front. Bioeng. Biotechnol. 8 https://doi.org/10.3389/fbioe.2020.00566.

Yamada, R., Wakita, K., Mitsui, R., Ogino, H., 2017. Enhanced D-lactic acid production by recombinant Saccharomyces cerevisiae following optimization of the global metabolic pathway. Biotechnol. Bioeng. 114 (9), 2075-2084. https://doi.org/ 10.1002/bit.26330.

Yan, D., Wang, C., Zhou, J., Liu, Y., Yang, M., Xing, J., 2014. Construction of reductive pathway in Saccharomyces cerevisiae for effective succinic acid fermentation at low pH value. Bioresour. Technol. 156, 232-239. https://doi.org/10.1016/j. biortech.2014.01.053.

Yan, Y., Bu, C., Huang, X., Ouyang, J., 2019. Efficient whole-cell biotransformation of furfural to furfuryl alcohol by Saccharomyces cerevisiae NL22. J. Chem. Technol. Biotechnol. 94, 3825-3831. https://doi.org/10.1002/jctb.6177.

Yang, C.-F., Huang, C.-R., 2016. Biotransformation of 5-hydroxy-methylfurfural into 2,5furan-dicarboxylic acid by bacterial isolate using thermal acid algal hydrolysate. Bioresour. Technol. 214, 311-318.

Yao, Z., Zhou, P., Su, B., Su, S., Ye, L., Yu, H., 2018. Enhanced Isoprene Production by Reconstruction of Metabolic Balance between Strengthened Precursor Supply and Improved Isoprene Synthase in Saccharomyces cerevisiae. ACS Synth. Biol. 7 (9), 2308-2316. https://doi.org/10.1021/acssynbio.8b00289.

Ye, L., Lv, X., Yu, H., 2016. Engineering microbes for isoprene production. Metab. Eng. 38, 125-138. https://doi.org/10.1016/j.ymben.2016.07.005.

Yin, X., Li, J., Shin, H.-D., Du, G., Liu, L., Chen, J., 2015. Metabolic engineering in the biotechnological production of organic acids in the tricarboxylic acid cycle of microorganisms: Advances and prospects. Biotechnol. Adv. 33 (6), 830-841. https:// doi.org/10.1016/j.biotechadv.2015.04.006.

Zanghellini, A. L., 2012. Fermentation route for the production of levulinic acid, levulinate esters, valerolactone, and deriveratives thereof. Internation patent nr. WO2012/030860A1.

Zhang, Z., Zhao, Z.K., 2010. Microwave-assisted conversion of lignocellulosic biomass into furans in ionic liquid. Bioresour. Technol. 101, 1111-1114.

Zhang, J., Li, J., Wu, S.-B., Liu, Y., 2013. Advances in the Catalytic Production and Utilization of Sorbitol. Ind. Eng. Chem. Res. 52, 11799-11815. https://doi.org/ 10.1021/ie4011854.

Zhao, X., Tang, J., Wang, X., Yang, R., Zhang, X., Gu, Y., Li, X., Ma, M., 2015. YNL134C from Saccharomyces cerevisiae encodes a novel protein with aldehyde reductase activity for detoxification of furfural derived from lignocellulosic biomass. Yeast 32, 409-422. https://doi.org/10.1002/yea.3068. 